\title{
Photochemistry of polycyclic aromatic hydrocarbons in cosmic water ice
}

\section{Mid-IR spectroscopy and photoproducts}

\author{
J. Bouwman ${ }^{1}$, A. L. Mattioda ${ }^{2}$, H. Linnartz ${ }^{1}$, and L. J. Allamandola ${ }^{2}$ \\ 1 Raymond and Beverly Sackler Laboratory for Astrophysics, Leiden Observatory, Leiden University, PO Box 9513, 2300 RA Leiden, \\ The Netherlands \\ e-mail: bouwman@strw. leidenuniv.nl \\ 2 NASA-Ames Research Center, Space Science Division, Mail Stop 245-6, Moffett Field, CA 94035, USA
}

Received 27 May 2010 / Accepted 23 September 2010

\begin{abstract}
Context. Polycyclic aromatic hydrocarbons (PAHs) are known to be abundantly present in photon-dominated regions (PDRs), as evidenced by their ubiquitous mid-IR emission bands. Towards dense clouds, however, their IR emission bands are strongly suppressed. It is here where molecules are known to reside on very cold grains $(T \leq 30 \mathrm{~K})$ in the form of interstellar ices. Therefore, it is likely that non-volatile species, such as PAHs, also freeze out on grains. Such icy grains act as catalytic sites and, upon vacuum ultraviolet (VUV) irradiation, chemical reactions are initiated. In the study presented here, these reactions and the resulting photoproducts are investigated for PAH containing water ices.

Aims. The aim of this work is to monitor vacuum ultraviolet induced chemical reactions of PAHs in cosmic ice through their IR signatures, to characterize the families of species formed in these reactions, and to apply the results to astronomical observations.

Methods. Mid-infrared Fourier transform absorption spectroscopic measurements ranging from 6500 to $450 \mathrm{~cm}^{-1}$ are performed on freshly deposited and vacuum ultraviolet processed PAH containing cosmic $\mathrm{H}_{2} \mathrm{O}$ ices at low temperatures.

Results. The mid-IR spectroscopy of anthracene, pyrene and benzo[ghi]perylene containing $\mathrm{H}_{2} \mathrm{O}$ ice is reported. Band strengths of the neutral PAH modes in $\mathrm{H}_{2} \mathrm{O}$ ice are derived. Additionally, spectra of vacuum ultraviolet processed $\mathrm{PAH}$ containing $\mathrm{H}_{2} \mathrm{O}$ ices are presented. These spectra are compared to spectra measured in VUV processed PAH:argon matrix isolation studies. It is concluded that the parent PAH species is ionized in $\mathrm{H}_{2} \mathrm{O}$ ice and that other photoproducts, mainly more complex PAH derivatives, also form. The importance of PAHs and their $\mathrm{PAH}: \mathrm{H}_{2} \mathrm{O}$ photoproducts in astronomical mid-infrared spectroscopic studies, in particular in the 5-8 $\mu \mathrm{m}$ region, is discussed. As a test-case, the VUV photolyzed $\mathrm{PAH}: \mathrm{H}_{2} \mathrm{O}$ laboratory spectra are compared to a high resolution ISOSWS spectrum of the high-mass embedded protostar W33A and to a Spitzer spectrum of the low-mass Young Stellar Object (YSO) RNO 91. For these objects, an upper limit of 2-3\% with respect to $\mathrm{H}_{2} \mathrm{O}$ ice is derived for the contribution of $\mathrm{PAHs}$ and $\mathrm{PAH}: \mathrm{H}_{2} \mathrm{O}$ photoproducts to the absorbance in the $5-8 \mu \mathrm{m}$ region towards these objects.
\end{abstract}

Key words. astrochemistry - molecular processes - methods: laboratory - techniques: spectroscopic - infrared: ISM ISM: abundances

\section{Introduction}

Polycyclic aromatic hydrocarbons (PAHs) are known to be abundantly present in photon-dominated regions (PDRs) (Peeters et al. 2004; van Dishoeck 2004; Tielens 2008). The evidence for the ubiquity of astronomical PAHs is the widespread, wellknown family of prominent emission bands at $3.28,6.2,7.6,8.6$, and $11.2 \mu \mathrm{m}\left(3050,1610,1300,1160\right.$, and $\left.890 \mathrm{~cm}^{-1}\right)$ associated with many, if not most, galactic and extragalactic objects (Smith et al. 2007; Draine \& Li 2007). These bands dominate the midIR emission spectrum because of an intrinsically high efficiency of the fluorescent process and are most easily detected in regions where individual gas-phase PAH molecules (both neutrals and ions) become highly vibrationally excited by the ambient UV-VIS-NIR radiation field (Mattioda et al. 2005a; Li \& Draine 2002). They then energetically relax by emission of IR photons at frequencies corresponding to fundamental vibrational modes, resulting in these well known emission spectra.

PAHs and related aromatic materials are expected to be present both in optically thin, diffuse regions of the ISM and in dense environments. In dense regions, however, the highly efficient PAH fluorescence is found to be quenched. There are two reasons for this. First, the radiation which pumps the emission tapers off with extinction into dense regions, and second, in cold molecular clouds PAHs can serve as nucleation sites on which other species condense. In this way, neutral and/or charged PAHs can agglomerate to form (charged) PAH clusters, or very small grains (VSGs) (e.g., Allamandola et al. 1989; Rapacioli et al. 2006). The VSGs can, subsequently, freeze out on grains or serve as nucleation sites for small molecules forming ice covered VSGs. Individual PAHs can also efficiently condense onto dust grains as "guest molecules" in icy grain mantles, much as is the case for most other smaller interstellar molecules (e.g., Sandford \& Allamandola 1993). Vibrational energy of a PAH molecule which is part of a larger dust particle, either as a nucleation center or guest in a water-rich ice, efficiently dissipates into the phonon modes of the solid material on a time-scale orders of magnitude shorter than required to emit an IR photon (Allamandola et al. 1985, 1989). Consequently, in dark, dense regions, PAHs and PAH derivatives are expected to give rise to IR absorption bands, not to emission features. 
There are several lines of evidence that support the presence of PAHs in dense molecular clouds. Aromatics in primitive meteorites and interplanetary dust particles contain deuterium enrichments that are best explained by an interstellar cloud heritage (e.g., Sandford 2002, and references therein). In addition, very weak absorption features attributed to aromatic hydrocarbons have been observed in the IR absorption spectra of objects embedded in dense clouds. These include a band near $3.3 \mu \mathrm{m}\left(3030 \mathrm{~cm}^{-1}\right)$ (Smith et al. 1989; Sellgren et al. 1995; Brooke et al. 1999; Chiar et al. 2000), and bands near $6.2 \mu \mathrm{m}\left(1600 \mathrm{~cm}^{-1}\right)\left(\right.$ Chiar et al. 2000) and $11.2 \mu \mathrm{m}\left(890 \mathrm{~cm}^{-1}\right)$ (Bregman et al. 2000). These very weak features are severely blended with much stronger $\mathrm{H}_{2} \mathrm{O}$ ice bands, consistent with the number of $\mathrm{PAH}$ molecules relative to the number of $\mathrm{H}_{2} \mathrm{O}$ molecules along these lines of sight on the order of a few percent. So far, it has proven difficult to unambiguously interpret these absorption features in spite of the fact that there is a growing database of theoretically calculated and laboratory measured IR absorption spectra of both neutral and ionized PAHs in inert matrices (e.g., Szczepanski \& Vala 1993; Szczepanski et al. 1993a,b, 1995a,b; Hudgins et al. 1994; Hudgins \& Allamandola 1995a, 1997; Langhoff 1996; Mattioda et al. 2005b; Bauschlicher et al. 2009, 2010, and references therein). Unfortunately, these spectra cannot be used directly to compare with PAHs in $\mathrm{H}_{2} \mathrm{O}$-rich ices, as rare gas matrix spectra will be different. Intermolecular interactions perturb the molecular vibrational energy levels, influencing IR band positions, widths, profiles, and intrinsic strengths. Consequently, it has not yet been possible to properly evaluate astronomical solid state PAH features, mainly because the corresponding laboratory data of realistic ice analogs are lacking.

Therefore, in the Astrochemistry Laboratory at NASA Ames Research Center a program to measure the IR spectra of PAHs in water ices was started. Earlier work focused on the IR band positions, band widths, and relative band strengths of neutral PAHs (Sandford et al. 2004; Bernstein et al. 2005a,b). More recently, an exploratory study of the effects of vacuum ultraviolet (VUV) photolysis on several $\mathrm{PAH}: \mathrm{H}_{2} \mathrm{O}$ ice mixtures was carried out (Bernstein et al. 2007). Unfortunately, at concentrations that are most appropriate for dense clouds, $\mathrm{PAH}$ bands are swamped in the mid-IR by overlapping $\mathrm{H}_{2} \mathrm{O}$ ice bands and it has proven difficult to put these IR-only data on a solid quantitative footing. This situation has recently changed thanks to the development of a new apparatus at the Sackler Laboratory for Astrophysics at Leiden University which allows one to track the in situ, VUV photochemistry of low concentration PAH: $\mathrm{H}_{2} \mathrm{O}$ ices (Bouwman et al. 2009, 2010a, in prep., 2010b) using optical (i.e. electronic) spectroscopy. This approach makes it possible to simultaneously follow the VUV driven kinetic behavior of the neutral parent $\mathrm{PAH}$ and photoproducts on millisecond timescales with a concentration precision on the order of a few percent. Using this approach, it was possible to characterize the VUV photochemistry of four PAHs anthracene, pyrene, benzo[ghi]perylene, and coronene in water ice at various concentrations and ice temperatures. This is described in detail in part II of this paper series (Bouwman et al. 2010a, in prep.). The mid-IR study presented here is partially based on the quantitative results derived in the optical work.

This paper is laid out as follows. After the experimental technique is described in Sect. 2, the results are presented in Sects. 3, 4 and 5. These include band profiles and band strengths for neutral anthracene, pyrene and benzo[ghi]perylene in $\mathrm{H}_{2} \mathrm{O}$ ice, the IR spectroscopic properties of their VUV induced photoproducts, and the visualization of photochemical processes at play
Table 1. Overview of the used ice mixtures, the PAH deposition temperatures, the resulting concentration, and the ice temperature during photolysis.

\begin{tabular}{lccc}
\hline \hline Ice $(\mathrm{PAH}: \mathrm{X})$ & $T_{\text {dep }}\left({ }^{\circ} \mathrm{C}\right)$ & Conc. $(\mathrm{PAH}: \mathrm{X})$ & $T_{\text {ice }}(\mathrm{K})$ \\
\hline Ant: $\mathrm{H}_{2} \mathrm{O}$ & 32 & $1: 450$ & 15 \\
& 42 & $1: 172$ & 15 \\
& 53 & $1: 60$ & 15 \\
& 71 & $1: 11$ & 15 \\
& 51 & $1: 100$ & 125 \\
$\mathrm{Py}: \mathrm{H}_{2} \mathrm{O}$ & 41 & $1: 200$ & 15 \\
& 44 & $1: 90$ & 15 \\
& 50 & $1: 65$ & 15 \\
& 51 & $1: 70$ & 125 \\
Py: $\mathrm{CO}$ & 50 & $1: 30$ & 15 \\
$\mathrm{~B}_{\text {ghi }} \mathrm{P}: \mathrm{H}_{2} \mathrm{O}$ & 143 & $1: 160$ & 15 \\
& 156 & $1: 60$ & 15 \\
& 152 & $1: 110$ & 125 \\
\hline
\end{tabular}

during extended photolysis. In Sect. 6 we extend our findings to the general IR properties of PAHs in ices and use these data to interpret observations of ices in dense clouds towards the high-mass protostar W33A and the low-mass young stellar object RNO 91. The conclusions are summarized in Sect. 7.

\section{Experimental technique}

The techniques employed in this study have been described in detail previously (Hudgins et al. 1994) and the relevant details are summarized briefly. The ices are prepared by vapor co-deposition of the PAH of interest with water vapor onto a $15 \mathrm{~K} \mathrm{CsI} \mathrm{window} \mathrm{which} \mathrm{is} \mathrm{suspended} \mathrm{in} \mathrm{a} \mathrm{high} \mathrm{vacuum} \mathrm{chamber}$ $\left(P \leq 10^{-8}\right.$ Torr). The PAHs anthracene (Ant, $\mathrm{C}_{14} \mathrm{H}_{10}$, Aldrich, $99 \%)$ and pyrene (Py, $\mathrm{C}_{16} \mathrm{H}_{10}$, Aldrich, 99\%) are used without further purification and vaporized from heated pyrex tubes. The PAH benzo[ghi]perylene ( $\mathrm{B}_{\text {ghi }} \mathrm{P}, \mathrm{C}_{22} \mathrm{H}_{12}$, Aldrich, $98 \%$ ) is kept at a temperature of $180^{\circ} \mathrm{C}$ for 20 min with a cold shield blocking the deposition onto the sample window to remove most of the contaminants and is subsequently deposited in a manner similar to that for Ant and Py. Simultaneously, water vapor milli-Q grade, further purified by three freeze-pump-thaw cycles - is admitted through an adjacent deposition tube. To prepare $\mathrm{PAH}: \mathrm{H}_{2} \mathrm{O}$ ices with different concentrations, the PAH deposition temperature was varied from one experiment to the other, while the water flow was kept constant. Mid-infrared spectroscopy of the PAHs Ant, Py, and $\mathrm{B}_{\text {ghi }} \mathrm{P}$ in water ice and for Py:CO ice as a control experiment is performed for a range of concentrations. The PAH deposition temperature, the resulting PAH concentration, and the ice temperature during photolysis are summarized in Table 1.

VUV photolysis of the sample ices is accomplished with the combined $121.6 \mathrm{~nm}$ Lyman- $\alpha(10.6 \mathrm{eV})$ and $160 \mathrm{~nm}(7.8 \mathrm{eV})$ molecular hydrogen emission bands from a microwave powered discharge in a flowing $\mathrm{H}_{2}$ gas at a dynamic pressure of 150 mTorr. The VUV radiation from the lamp enters the sample chamber through a $\mathrm{MgF}_{2}$ window. The UV photon flux of the lamp is $\sim 10^{15}$ photons $\mathrm{cm}^{-2} \mathrm{~s}^{-1}$ at the sample surface.

Spectra from 6500 to $450 \mathrm{~cm}^{-1}$ are measured with a Biorad Excalibur FTS 4000 FTIR spectrometer equipped with a $\mathrm{KBr}$ beamsplitter and a liquid $\mathrm{N}_{2}$-cooled MCT detector. Spectra are taken in optical depth $\left(\tau=\ln \left(I / I_{0}\right)\right)$, with the background spectrum $\left(I_{0}\right)$ taken on the cold sample window before sample deposition, and the spectra $(I)$ taken after deposition and 


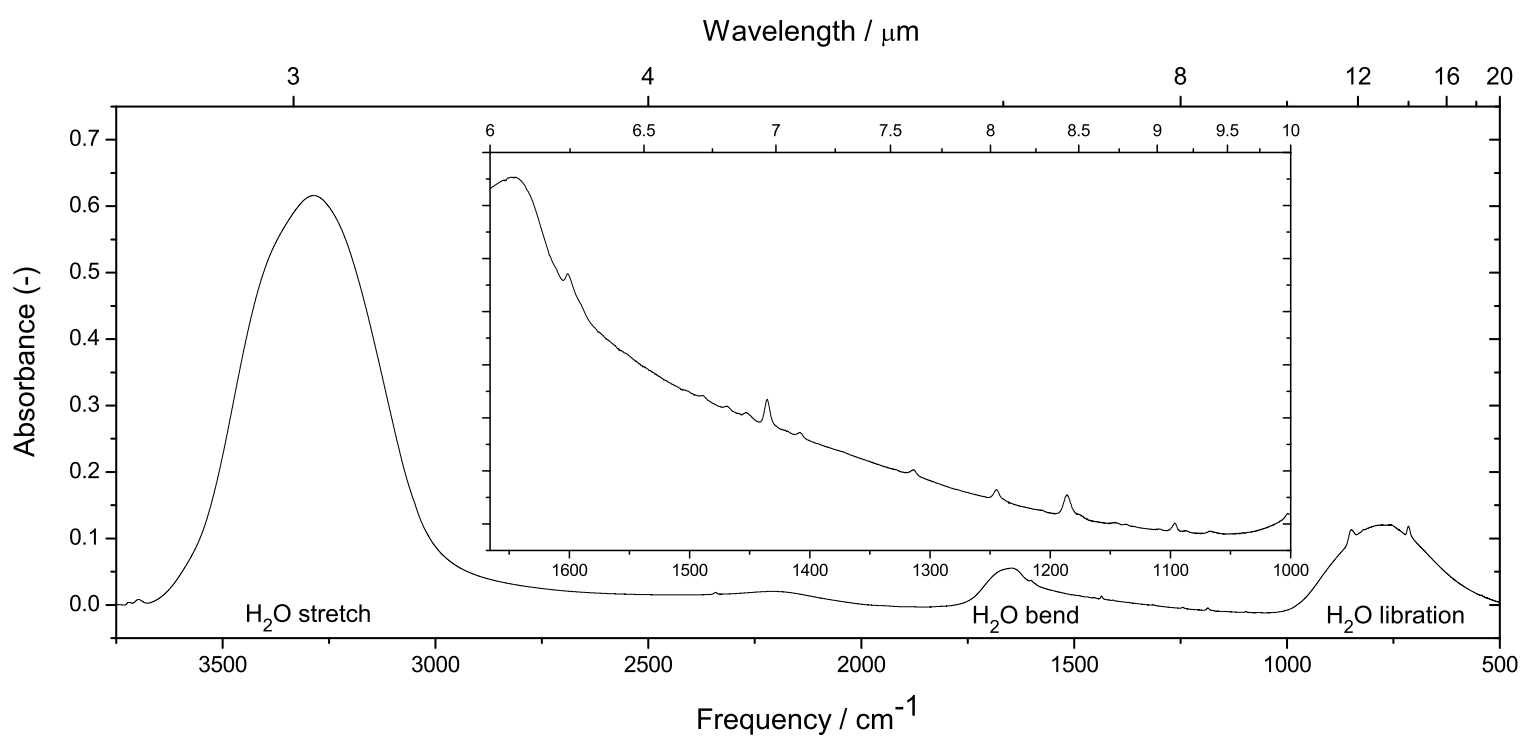

Fig. 1. A typical absorption spectrum for a pyrene: $\mathrm{H}_{2} \mathrm{O}(1: 90)$ ice mixture at $15 \mathrm{~K}$. The inset shows a blow-up of that part of the spectrum (region of interest) where Py absorptions are least affected by the water modes. The water modes are labeled in the spectrum.

VUV processing of the sample. Each spectrum represents a coaddition of 512 spectra at a resolution of $0.5 \mathrm{~cm}^{-1}$. This level of resolution is necessary to distinguish photoproduct bands that are close to the position of the neutral band. The number of scans was chosen to optimize both the signal-to-noise ratio as well as the time requirements for each experiment. Spectra are taken at $15 \mathrm{~K}$ of the freshly deposited sample and after $5,10,15,30,60$, 120, and 180 min of VUV photolysis. Similar measurements are also performed on $\mathrm{PAH}: \mathrm{H}_{2} \mathrm{O}$ ice samples at $125 \mathrm{~K}$ to check for differences in photochemistry between low and high temperature photolysis experiments.

We focus on the bands in the $1650-1000 \mathrm{~cm}^{-1}$ region because this is where the PAH mid-IR bands suffer the least from overlap with the strong $\mathrm{H}_{2} \mathrm{O}$ ice features (Fig. 1). Hereafter we refer to this as the Region Of Interest (ROI). The absolute band strengths for the neutral PAH modes in $\mathrm{H}_{2} \mathrm{O}$ ice are derived as follows. The $\mathrm{H}_{2} \mathrm{O}$ bending and librational overtone modes are subtracted from the raw spectrum by fitting a spline function through a set of points where no PAH absorption occurs. Subsequently, the total theoretically calculated absolute intensity in the ROI is proportionally divided over the measured PAH modes in this frequency range, via:

$A_{i}^{\exp }=\left[\sum_{j=0}^{M} A_{j}^{\text {thy }}\right] \frac{\int_{v_{i, 1}}^{v_{i, 2}} \tau_{i, v} \mathrm{~d} v}{\sum_{i=0}^{L} \int_{v_{i, 1}}^{v_{i, 2}} \tau_{i, v} \mathrm{~d} \nu}$,

where $A_{i}^{\exp }$ is the experimentally measured band strength of PAH mode $i$ in $\mathrm{H}_{2} \mathrm{O}$ ice in cm molecule ${ }^{-1}, A_{j}^{\text {thy }}$ is the theoretically calculated absolute intensity of vibrational mode $j$ in the ROI in $\mathrm{cm}$ molecule ${ }^{-1}, M$ is the number of theoretically calculated modes in the ROI, $\tau_{i, v}$ is the optical depth of mode $i$ in $\mathrm{H}_{2} \mathrm{O}$ ice at frequency $v\left(\mathrm{~cm}^{-1}\right), L$ is the number of measured modes in the ROI, and $v_{i, 1}$ and $v_{i, 2}$ are the lower and upper integration boundaries in $\mathrm{cm}^{-1}$, respectively, for absorption feature $i$. This method takes advantage of the fact that, although there may be band-toband variations in the accuracy of the calculated intensity for one band, the total theoretically calculated intensity is generally accurate to within $10-20 \%$. Here we assume that the matrix material does not substantially influence the total integrated
IR band intensity and, as will be shown later, this is only an approximation.

The PAH in $\mathrm{H}_{2} \mathrm{O}$ concentrations are determined as follows. The optical depths $\left(\tau_{v}\right)$ of the $3 \mu \mathrm{m}$ stretching, $6 \mu \mathrm{m}$ bending, and $13 \mu \mathrm{m}$ libration modes of water are integrated over the frequency domain $\left(v\right.$ in $\left.\mathrm{cm}^{-1}\right)$ and converted into the column density ( $N$ in molecules $\mathrm{cm}^{-2}$ ), using the well known $\mathrm{H}_{2} \mathrm{O}$ band strength values $A_{\text {band }}$ (Hudgins et al. 1993), via:

$N=\frac{\int \tau_{\nu} \mathrm{d} \nu}{A_{\text {band }}}$.

The adopted $\mathrm{H}_{2} \mathrm{O}$ band strength values, $A_{\text {band }}$, are $2 \times 10^{-16}$, $1.2 \times 10^{-17}$ and $3.1 \times 10^{-17} \mathrm{~cm} \mathrm{molecule}^{-1}$ for the stretching, bending and libration mode, respectively. The $\mathrm{H}_{2} \mathrm{O}$ column density is determined by taking the average of these three strong $\mathrm{H}_{2} \mathrm{O}$ bands. Similarly, at least four strong bands of the PAHs under investigation are integrated and converted to column densities using the band strengths for these modes as calculated above (Eq. (1)). The average PAH column density is used to determine the concentration, which is given by the ratio of the $\mathrm{PAH}$ and $\mathrm{H}_{2} \mathrm{O}$ column densities.

Comparison of the PAH: $\mathrm{H}_{2} \mathrm{O}$ ice spectrum before photolysis to that measured after photolysis permits identification of photoproduct features, including cation absorption bands. The spectrum of the freshly deposited $\mathrm{PAH}: \mathrm{H}_{2} \mathrm{O}$ ice, multiplied by a factor, $Y(0 \leq Y \leq 1)$, is used as a reference that is subtracted from the spectrum of the irradiated ice using the Resolutions Pro spectrometer software package provided by Biorad. The factor $Y$ is varied until the neutral bands are removed from the spectrum. At this point, the resulting subtraction spectrum reveals only the photoproduct bands and the subtraction factor, $Y$, directly reflects the amount of neutral $\mathrm{PAH}$ consumed during photolysis. Additionally, the remaining contributions from the $\mathrm{H}_{2} \mathrm{O}$ librational overtone and $\mathrm{H}_{2} \mathrm{O}$ bending mode are subtracted by a spline function, for which points are chosen at positions where no PAH photoproduct absorptions are observed. The resulting baseline corrected spectra are used for further analysis.

The sample window on which the ices are grown was thoroughly cleaned before commencing experiments on a different $\mathrm{PAH}$. Thus, the background spectrum taken of the cold sample 
window before starting a series of measurements $\left(I_{0}\right)$ was free of PAH absorptions. For one specific PAH, typically five individual PAH: $\mathrm{H}_{2} \mathrm{O}$ photolysis experiments were performed for different concentrations and temperatures (Table 1), during which a residue built up, comprising unprocessed $\mathrm{PAH}$, and presumably also PAH: $\mathrm{H}_{2} \mathrm{O}$ photoproducts. After completion of the measurement series for this specific PAH, a spectrum (I) was taken of the room temperature "dirty" sample window. Subsequently, the system was cleaned and prepared for the next run. The ratio $\ln \left(I / I_{0}\right)$ reflects the optical depth spectrum of the non-volatile residue and is used to derive complementary information on the species formed in the ice. The non-volatile residues that built up during the Ant, $\mathrm{Py}$, and $\mathrm{B}_{\text {ghi }} \mathrm{P}$ measurement series are discussed in Sect. 5.

\section{PAH: $\mathrm{H}_{2} \mathrm{O}$ spectroscopy}

Earlier observations (Smith et al. 1989; Sellgren et al. 1995; Brooke et al. 1999; Chiar et al. 2000; Bregman et al. 2000) indicate that the ratio of the number of PAH molecules to the number of $\mathrm{H}_{2} \mathrm{O}$ ice molecules is small along lines of sight towards protostars in dense clouds. Based on these observations, we deduce that this number seems to be on the order of a few percent. In a very careful study, Sellgren et al. (1995) reported the optical depth of the $3.25 \mu \mathrm{m}$ aromatic $\mathrm{C}-\mathrm{H}$ stretch band towards Mon R2/IRS 3 as 0.045 with a $F W H M$ of $75 \mathrm{~cm}^{-1}$. These values are similar to the range of values reported by Bregman \& Temi (2001) towards other deeply embedded protostars. For the purposes of this analysis, we use the results from Sellgren et al. (1995). Similar conclusions can be drawn using the observations from these other lines of sight.

Using the standard equation to determine the column density of absorbers along a given line of sight:

$N=\frac{\tau \times F W H M}{A}$,

with the $F W H M$ in $\mathrm{cm}^{-1}$ and an $A$ value of $2.5 \times 10^{-18} \mathrm{~cm}$ per aromatic $\mathrm{C}-\mathrm{H}$ bond (e.g. Joblin et al. 1994; Bauschlicher et al. 2008) yields $1.4 \times 10^{18}$ aromatic $\mathrm{C}-\mathrm{H}$ groups per $\mathrm{cm}^{2}$ along the line of sight to Mon R2/IRS 3. Astronomical PAHs are thought to range in size from roughly $\mathrm{C}_{25}$ to well over $\mathrm{C}_{100}$. Reasonable formulae for such sized species are $\mathrm{C}_{32} \mathrm{H}_{15}$ and $\mathrm{C}_{130} \mathrm{H}_{28}$. To take this into account, we estimate that the "average" number of aromatic $\mathrm{C}-\mathrm{H}$ bonds per astronomical $\mathrm{PAH}$ is 25 . Dividing the column density of aromatic $\mathrm{C}-\mathrm{H}$ bonds towards Mon R2/IRS $3\left(1.4 \times 10^{18}\right)$ by 25 yields the PAH column density, $5.4 \times 10^{16} \mathrm{PAHs} \mathrm{cm}{ }^{-2}$. Likewise, for Mon R2/IRS 3 we derive $3.3 \times 10^{18} \mathrm{H}_{2} \mathrm{O}$ ice molecules $\mathrm{cm}^{-2}$ from the $\mathrm{O}-\mathrm{H}$ stretch band in Smith et al. (1989). Thus, the $\mathrm{PAH} / \mathrm{H}_{2} \mathrm{O}$ ice ratio along this line of sight is $5.4 \times 10^{16} / 3.3 \times 10^{18}=0.016$, or $2 \%$.

Figure 1 presents the $3750-500 \mathrm{~cm}^{-1}$ spectrum of a $\mathrm{Py}: \mathrm{H}_{2} \mathrm{O}$ (1:90) ice at $15 \mathrm{~K}$, which clearly shows that the $\mathrm{H}_{2} \mathrm{O}$ ice bands dominate the spectrum at these concentrations. In agreement with earlier findings on other PAHs at concentrations of a few percent in $\mathrm{H}_{2} \mathrm{O}$ ice, the $\mathrm{CH}$-stretch band near $3030 \mathrm{~cm}^{-1}$ $(3.3 \mu \mathrm{m})$ is nearly imperceptible, while the strong $\mathrm{C}-\mathrm{H}$ out-ofplane bending bands between $900-500 \mathrm{~cm}^{-1}(11-20 \mu \mathrm{m})$ suffer from severe blending with the $\mathrm{H}_{2} \mathrm{O}$ ice libration mode (Sandford et al. 2004; Bernstein et al. 2005a). This makes PAH bands between $1650-1000 \mathrm{~cm}^{-1}(\sim 6.06-10 \mu \mathrm{m}$, the ROI) the most promising to study $\mathrm{PAH}: \mathrm{H}_{2} \mathrm{O}$ photochemistry, and to identify astronomical PAHs and PAH related photoproduct species in interstellar ices.
The spectroscopy of PAH: $\mathrm{H}_{2} \mathrm{O}$ ice samples is discussed for Ant, $\mathrm{Py}$, and $\mathrm{B}_{\text {ghi }} \mathrm{P}$ and compared to available $\mathrm{PAH}$ matrix isolation data. In Fig. 2 typical baseline corrected spectra of the three neutral PAHs in argon (trace A) are plotted together with the spectra of the neutral PAH: $\mathrm{H}_{2} \mathrm{O}$ (trace B) ice $(\sim 1: 60)$. The spectra are normalized to the strongest absorptions in the ROI. Clearly, the absorption bands are much broader in water ice compared to the argon matrix data, causing some of the absorption bands to overlap. Furthermore, the relative intensities of the bands differ for an argon or $\mathrm{H}_{2} \mathrm{O}$ environment. The band positions and integrated absorbances relative to that of the strongest $\mathrm{PAH}$ absorption are listed in Table 2 for Ant, $\mathrm{Py}$ and $\mathrm{B}_{\text {ghi }} \mathrm{P}$ in $\mathrm{H}_{2} \mathrm{O}$ ice and in an argon matrix (Hudgins \& Sandford 1998a). The corresponding Density Functional Theory (DFT) peak positions taken from Langhoff (1996) are given as well. The absolute band strengths for PAHs in $\mathrm{H}_{2} \mathrm{O}$ ice, calculated under the assumptions described in Sect. 2, are also listed in Table 2. Within the errors, the $F W H M$, relative intensity, and position of the band maximum of absorptions of the three species studied here are found to be independent of concentration and temperature for the values listed in Table 1, even for the two most extreme Ant: $\mathrm{H}_{2} \mathrm{O}$ ice concentrations (1:11 and 1:450). Thus, although we cannot fully exclude the presence of PAH aggregates in the ice, there is no spectral evidence for such species.

\section{PAH ice photochemistry}

All PAH: $\mathrm{H}_{2} \mathrm{O}$ ice samples listed in Table 1 are VUV irradiated for $5,10,15,30,60,120$, and $180 \mathrm{~min}$. Mid-IR spectra are taken after each VUV dose to look for changes in the spectrum. Spline baseline corrected spectra after $5 \mathrm{~min}$ of VUV irradiation of the Ant, $\mathrm{Py}$, and $\mathrm{B}_{\text {ghi }} \mathrm{P}$ containing $\mathrm{H}_{2} \mathrm{O}$ ice samples with a mixing ratio of $\sim 1: 60$ are shown in trace (D) of Fig. 2. In this figure, the spectra are compared to those of the corresponding $\mathrm{PAH}^{+}$species produced and trapped in solid argon (trace C). Comparison of the traces (D) and (B) in Fig. 2 shows that new absorptions arise upon photolysis of the PAH: $\mathrm{H}_{2} \mathrm{O}$ mixtures. The photoproduct features are, however, heavily blended with those of the remaining neutral PAH. To overcome this, spectra of freshly deposited PAHs are subtracted from their VUV photolyzed counterparts with a subtraction factor, $Y$, as described in Sect. 2. Subsequently, the contribution by the librational overtone and the $\mathrm{H}_{2} \mathrm{O}$ bending mode are removed by fitting and subtracting a spline function. The resulting spectra are shown in trace (E) of Fig. 2 and show photoproducts only. The spectra are again scaled to the strongest absorption in the ROI. It has to be noted here, that the absorption bands of the photoproducts after 5 min of VUV irradiation are rather small compared to those of the neutral bands, as can be seen by comparing trace (B) and (D) from Fig. 2. While band intensities grow with longer irradiation time, the combination of spectral overlap and different photoproduct band growths and losses makes it difficult to track the precise photochemistry at longer photolysis times. This is discussed later in Sect. 4.2.

It is clear from Table 2 that the relative PAH band strengths in $\mathrm{H}_{2} \mathrm{O}$ ice are different from those in an argon matrix, but the PAH cation band strengths measured in argon have to be used for further analysis, since band strength values for PAH cation vibrational modes in $\mathrm{H}_{2} \mathrm{O}$ ice cannot be reliably determined for two reasons. First, the appearance of bands other than cation absorptions after $5 \mathrm{~min}$ of photolysis points out that there is no one-to-one conversion of the neutral PAH to the cation and, thus, the column density of used up neutral PAH molecules cannot be used as a reliable column density for cations in the ice on which 


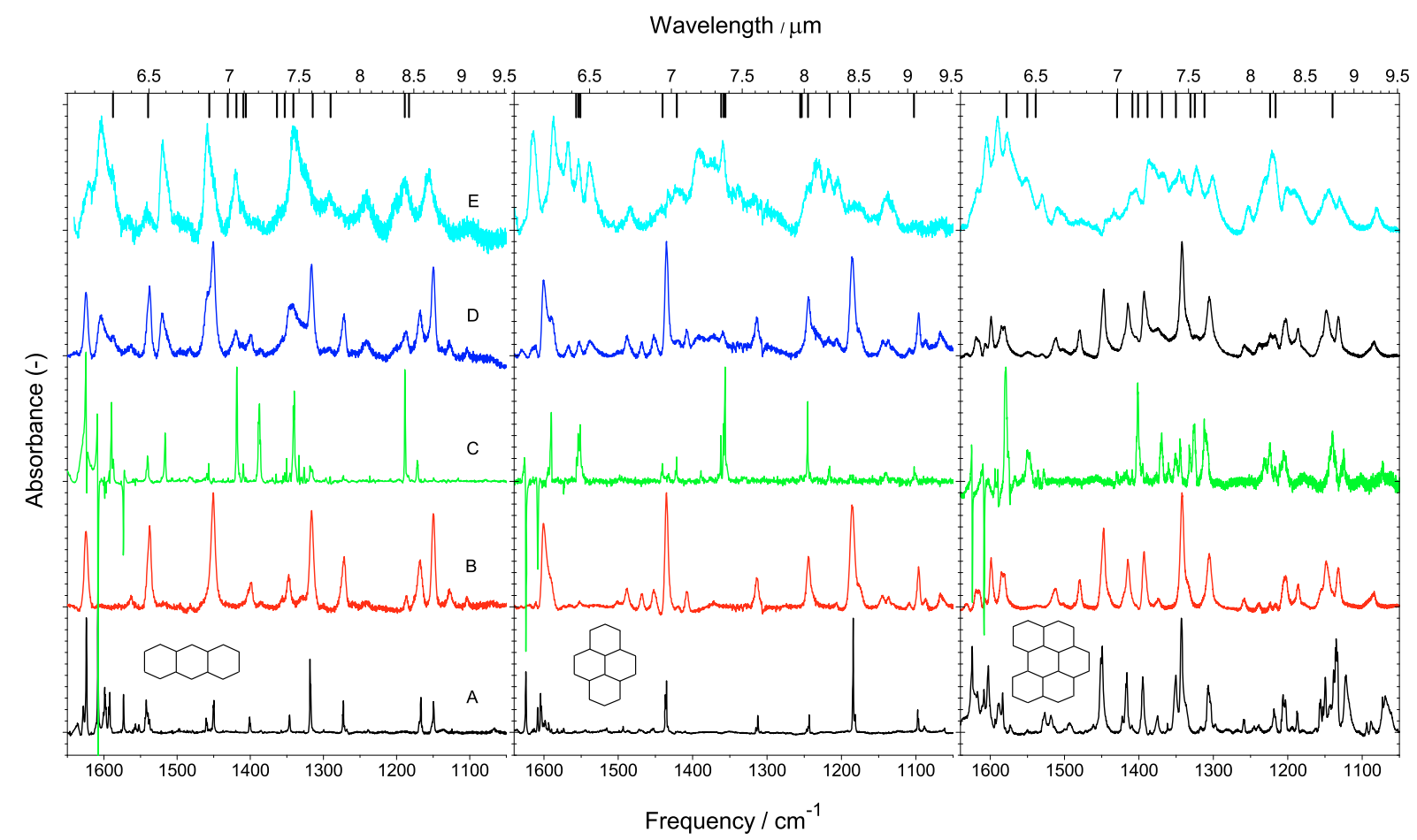

Fig. 2. From left to right the 1640 to $1050 \mathrm{~cm}^{-1}$ spectra of the PAHs anthracene, pyrene, and benzo[ghi]perylene considered are shown here. A) Spectra of the neutral PAH in argon; B) spectra of the neutral PAH in water ice; C) spectra of the PAH cation in argon; D) spectra of the PAH: $\mathrm{H}_{2} \mathrm{O}$ mixture after 5 min of in situ VUV photolysis; and $\mathbf{E}$ ) spectra showing only the photoproduct features that appear after 5 min of in situ VUV photolysis of the PAH: $\mathrm{H}_{2} \mathrm{O}$ ice (spectrum "D" $-Y \times$ "B"). The tick marks connected to the top axis indicate the positions of PAH ${ }^{+}$features measured in argon. The PAH:matrix concentrations and temperatures for the spectra shown in A and $\mathrm{B}$ are: Ant:Ar $<1: 1000,10 \mathrm{~K} ; \mathrm{Py}$ :Ar $<1: 1000$, $10 \mathrm{~K} ; \mathrm{B}_{\text {ghi }} \mathrm{P}: \mathrm{Ar}<1: 1000,10 \mathrm{~K}$ and Ant: $\mathrm{H}_{2} \mathrm{O}=1: 60,15 \mathrm{~K} ; \mathrm{Py}: \mathrm{H}_{2} \mathrm{O}=1: 65,15 \mathrm{~K} ; \mathrm{B}_{\text {ghi }} \mathrm{P}: \mathrm{H}_{2} \mathrm{O}=1: 60,15 \mathrm{~K}$. Argon matrix spectra of neutral Ant and Py are reproduced from Hudgins \& Sandford (1998a), neutral $\mathrm{B}_{\text {ghi }} \mathrm{P}$ from Hudgins \& Sandford (1998b), ionized Ant from Hudgins \& Allamandola (1995b), and ionized Py and $B_{\text {ghi }}$ P from Hudgins \& Allamandola (1995a).

to base a further band strength analysis. Secondly, spectral congestion and ill-defined baselines make it hard to obtain accurate band areas of photoproduct bands in irradiated mixtures. This choice induces additional errors in the absolute $\mathrm{PAH}^{+}$column density that can be as high as a factor of two.

\section{1. $\mathrm{PAH}: \mathrm{H}_{2} \mathrm{O}$ photoproducts}

VUV photoprocessed PAH containing $\mathrm{H}_{2} \mathrm{O}$ ices spectra exhibit a set of broad absorption features (see trace E of Fig. 2). As with the neutral PAHs, the absorption profiles of PAH photoproducts in $\mathrm{H}_{2} \mathrm{O}$ ice are much broader than those in an argon matrix (trace $\mathrm{C}$ ). These $\mathrm{PAH}: \mathrm{H}_{2} \mathrm{O}$ photoproduct absorption bands are decomposed by multiple Gaussian fits and the peak positions of these bands are listed together with $\mathrm{PAH}^{+}$absorptions and band strengths measured in argon in Table 3. The solid lines along the top margin indicate the PAH cation band positions in Ar (Hudgins \& Allamandola 1995a,b). The photoproduct bands that fall within $10 \mathrm{~cm}^{-1}$ of these features are assigned to the $\mathrm{PAH}^{+}$bands in $\mathrm{H}_{2} \mathrm{O}$. Some of the newly formed absorption bands, however, occur at positions where no corresponding $\mathrm{PAH}^{+}$band is found in argon. These absorption bands reflect additional chemical reactions already at play in the early photolysis of $\mathrm{PAH}: \mathrm{H}_{2} \mathrm{O}$ ices.

It is well known that $\mathrm{H}_{2} \mathrm{O}$ molecules photodissociate into radicals $(\mathrm{H}+\mathrm{OH})$ and that these radicals are mobile within $\mathrm{H}_{2} \mathrm{O}$ ice, even at low temperatures (Andersson \& van Dishoeck 2008; Öberg et al. 2009). At the concentrations under consideration here, it is therefore likely that these and other photoproducts react with the PAHs, forming more complex aromatic species containing functional groups that give rise to different peak positions in the mid-IR spectra (see also Bouwman et al. 2010b and the discussion in Gudipati \& Allamandola 2006). While infrared spectroscopic data on $\mathrm{PAH}: \mathrm{H}_{2} \mathrm{O}$ photoproducts are largely lacking in the literature, analysis of the non-volatile photoproducts after warm-up (i.e. thermal processing) has shown that the O, $\mathrm{OH}$ and $\mathrm{H}$ additions to the parent $\mathrm{PAH}$ are the dominant reaction pathways (Ashbourn et al. 2007; Bernstein et al. 1999, 2002). Aromatic alcohols are among the known photoproducts, and the $\mathrm{C}-\mathrm{O}$ stretching vibration in alcohols and phenols produces a strong band in the $1260-1000 \mathrm{~cm}^{-1}$ region (e.g., Silverstein \& Bassler 1967). Additionally, the alcohol $\mathrm{OH}$ wag falls in the 1420 to $1330 \mathrm{~cm}^{-1}$ region. Besides alcohols, aromatic ketones are also amongst the photoproducts. The $\mathrm{C}=\mathrm{O}$ stretch vibration in ketones typically occurs at around $1700 \mathrm{~cm}^{-1}$. Keeping this in mind, tentative identifications of unassigned bands, i.e. not due to $\mathrm{PAH}^{+}$, are made below.

\subsubsection{Anthracene: $\mathrm{H}_{2} \mathrm{O}$ photoproducts}

While most of the bands in the spectrum of the Ant: $\mathrm{H}_{2} \mathrm{O}$ photoproducts can be attributed to $\mathrm{Ant}^{+}$, some prominent bands cannot. Two such bands appear at 1156 and $1243 \mathrm{~cm}^{-1}$. It is possible that both of these absorptions originate from the $\mathrm{CO}$ stretch of two different Ant-OH isomers. The $1243 \mathrm{~cm}^{-1}$ band was previously attributed to an unknown $\mathrm{Ant}: \mathrm{H}_{2} \mathrm{O}$ photoproduct (Bernstein et al. 2007). Another prominent band that is not solely due to $\mathrm{Ant}^{+}$occurs at $1452 \mathrm{~cm}^{-1}$. While a small 
Table 2. The band positions and relative integrated absorbances for the studied PAHs in $\mathrm{H}_{2} \mathrm{O}$ ice at $15 \mathrm{~K}$, and in an argon matrix at $10 \mathrm{~K}$, as well as band positions computed using DFT.

\begin{tabular}{|c|c|c|c|c|c|c|}
\hline \multirow[t]{2}{*}{$\mathrm{PAH}$} & \multicolumn{3}{|c|}{ Position $\left(\mathrm{cm}^{-1}\right)$} & \multicolumn{2}{|c|}{ Relative I.A. } & \multirow{2}{*}{$\begin{array}{c}A_{\text {band }}{ }^{a} \\
\mathrm{H}_{2} \mathrm{O}\end{array}$} \\
\hline & $\mathrm{H}_{2} \mathrm{O}$ & $\mathrm{Ar}$ & Theory $^{b}$ & $\mathrm{H}_{2} \mathrm{O}$ & $\mathrm{Ar}$ & \\
\hline \multirow[t]{18}{*}{ Ant } & 1001.7 & 1000.9 & 1000.7 & 0.7 & 0.8 & 6.8 \\
\hline & 1103.8 & & & 0.1 & & 0.8 \\
\hline & 1127.4 & & & 0.2 & & 1.9 \\
\hline & 1149.7 & 1149.2 & 1156.2 & 0.9 & 0.7 & 9.0 \\
\hline & & & 1157.7 & & & \\
\hline & 1168.2 & 1166.9 & 1169.3 & 0.6 & 0.5 & 6.2 \\
\hline & 1186.8 & & & 0.1 & & 1.0 \\
\hline & 1272.3 & 1272.5 & 1274.6 & 0.5 & 0.6 & 5.7 \\
\hline & 1316.0 & 1318.1 & 1311.2 & 1.0 & 1.0 & 10.4 \\
\hline & 1328.3 & & & 0.2 & & 2.1 \\
\hline & 1347.7 & $1345.6,1346.4$ & 1342.6 & 0.3 & 0.2 & 3.5 \\
\hline & 1400.1 & & & 0.3 & & 3.1 \\
\hline & 1450.9 & 1450.5 & 1455.3 & 1.4 & 0.4 & 14.6 \\
\hline & & 1460.0 & 1456.1 & & 0.3 & \\
\hline & 1537.9 & 1542.0 & 1533.7 & 0.8 & 0.8 & 8.7 \\
\hline & 1563.1 & & & 0.1 & & 0.8 \\
\hline & & 1610.5 & 1620.0 & & 0.2 & \\
\hline & 1624.4 & 1627.8 & & 0.8 & 0.4 & 7.9 \\
\hline \multirow[t]{14}{*}{ Py } & 1065.5 & & & 0.1 & & 2.8 \\
\hline & 1096.4 & 1097.3 & 1092.3 & 0.2 & 0.2 & 5.1 \\
\hline & 1136.6 & & & 0.1 & & 2.1 \\
\hline & 1176.3 & 1164.5 & 1160.8 & 0.3 & 0.1 & 6.1 \\
\hline & 1185.6 & 1183.9 & 1188.3 & 1.0 & 1.0 & 21.7 \\
\hline & 1244.0 & 1243.0 & 1253.1 & 0.5 & 0.2 & 10.3 \\
\hline & 1313.7 & 1312.1 & 1314.6 & 0.2 & 0.2 & 5.3 \\
\hline & 1435.1 & 1434.8 & 1427.0 & 0.8 & 0.6 & 17.3 \\
\hline & & & 1427.5 & & & \\
\hline & 1452.0 & & & 0.1 & & 2.8 \\
\hline & 1468.4 & 1471.0 & 1476.2 & 0.1 & 0.1 & 1.8 \\
\hline & 1488.4 & & & 0.2 & & 3.3 \\
\hline & 1594.1 & & 1586.1 & 0.6 & & 12.7 \\
\hline & 1600.5 & 1604.0 & 1597.0 & 0.6 & 0.4 & 12.0 \\
\hline \multirow{25}{*}{$\mathrm{B}_{\text {ghi }} \mathrm{P}$} & 1038.3 & 1036.3 & 1037.6 & 0.2 & 0.1 & 4.4 \\
\hline & 1085.9 & 1087.8 & 1082.2 & 0.2 & 0.0 & 3.6 \\
\hline & & 1093.4 & 1091.9 & & 0.0 & \\
\hline & 1132.0 & 1132.7 & 1136.6 & 0.4 & 0.3 & 8.5 \\
\hline & 1148.0 & 1149.2 & 1152.7 & 0.8 & 0.1 & 17.8 \\
\hline & 1186.5 & 1186.9 & 1171.1 & 0.3 & 0.0 & 6.2 \\
\hline & & & 1206.6 & & & \\
\hline & 1203.5 & 1206.7 & 1203.3 & 0.5 & 0.3 & 10.8 \\
\hline & 1258.7 & 1259.1 & 1261.5 & 0.1 & 0.0 & 1.7 \\
\hline & & & 1309.0 & & & \\
\hline & 1305.6 & $1302.9,1307.0$ & 1292.3 & 0.7 & 0.3 & 15.8 \\
\hline & 1334.6 & & 1338.6 & 0.3 & & 6.3 \\
\hline & 1342.2 & 1342.6 & 1336.0 & 1.0 & 1.0 & 22.5 \\
\hline & 1374.9 & 1350.0 & 1375.8 & 0.1 & 0.2 & 1.6 \\
\hline & & & 1398.9 & & & \\
\hline & 1392.8 & 1394.7 & 1397.8 & 0.5 & 0.4 & 11.7 \\
\hline & 1414.8 & $1416.0,1417.1$ & 1426.2 & 0.5 & 0.3 & 11.4 \\
\hline & 1447.8 & $1449.0,1451.1$ & 1441.3 & 0.8 & 0.6 & 17.8 \\
\hline & 1479.7 & & & 0.2 & & 4.7 \\
\hline & 1512.8 & 1517.8 & 1513.3 & 0.2 & 0.0 & 3.5 \\
\hline & & 1527.4 & & & 0.1 & \\
\hline & 1582.8 & 1602.1 & 1586.4 & 0.4 & 0.2 & 9.1 \\
\hline & 1598.5 & & 1586.6 & 0.3 & & 6.5 \\
\hline & 1614.7 & & & 0.1 & & 1.3 \\
\hline & 1618.9 & & & 0.1 & & 2.4 \\
\hline
\end{tabular}

Notes. ${ }^{(a)}$ The absolute intensities $\left(A_{\text {band }}\right.$ ) for the PAHs in $\mathrm{H}_{2} \mathrm{O}$ ice are in units $10^{-19} \mathrm{~cm} /$ molecule. ${ }^{(b)}$ Values taken from: Langhoff (1996).

cation band is present near this position in the argon matrix data, it is much less intense with respect to the other cation bands whereas the photoproduct band in trace (E) (Fig. 2) is one of the strongest in the spectrum. This band is likely a blend of the cation band with a much stronger product band. The absorption frequency suggests that it originates from an aromatic $\mathrm{CC}$ stretching and $\mathrm{C}-\mathrm{H}$ in-plane bending mode. Two strong photoproduct bands also appear in the blue end of the ROI, one at $1518 \mathrm{~cm}^{-1}$, the other at $1604 \mathrm{~cm}^{-1}$. The moderately strong $\mathrm{Ant}^{+}$ band at $1586.4 \mathrm{~cm}^{-1}$ is expected to contribute to the blue end of the $1604 \mathrm{~cm}^{-1}$ feature, but again seems to be too weak to explain the full feature. Both the $1518 \mathrm{~cm}^{-1}$ and most of the $1604 \mathrm{~cm}^{-1}$ bands are likely due to the aromatic $\mathrm{CC}$ stretch vibration of a newly formed species.

The detection of new bands in the $1260-1000 \mathrm{~cm}^{-1}$ region upon VUV photolysis of an Ant: $\mathrm{H}_{2} \mathrm{O}$ mixture does agree with earlier findings by Ashbourn et al. (2007), who detected 1-anthrol and 2-anthrol using HPLC in a VUV irradiated Ant: $\mathrm{H}_{2} \mathrm{O}$ ice $(>1: 100)$ after warm-up to room temperature. They also reported the formation of 1,4-anthraquinone, 9,10-anthraquinone and 9-anthrone. Anthraquinones contain two $\mathrm{C}=\mathrm{O}$ bonds, which typically absorb at a frequency of $1676 \mathrm{~cm}^{-1}$ (Chumbalov et al. 1967). This band position is outside of our ROI and detection is hampered by the strong $\mathrm{H}_{2} \mathrm{O}$ bending mode. The other species detected by Ashbourn et al. (2007), 9-anthrone, belongs to the group of ketones and is expected to exhibit a $\mathrm{C}=\mathrm{O}$ absorption at $\sim 1700 \mathrm{~cm}^{-1}$. The formation of this species can also not be confirmed for the same reason.

\subsubsection{Pyrene: $\mathrm{H}_{2} \mathrm{O}$ photoproducts}

In the Py: $\mathrm{H}_{2} \mathrm{O}$ case, the spectra in Fig. 2, trace (E) and photoproduct peak positions listed in Table 3 show that less than half of the new bands can be confidently assigned to $\mathrm{Py}^{+}$. As discussed above for Ant, the new features between 1260 and $1000 \mathrm{~cm}^{-1}$ may be due to the $\mathrm{CO}$ stretch in various $\mathrm{Py}-\mathrm{OH}$ isomers. Likewise, the prominent features at 1373 and $1393 \mathrm{~cm}^{-1}$ can be tentatively attributed to modes involving both aromatic $\mathrm{CC}$ stretch and $\mathrm{C}-\mathrm{H}$ in-plane bends of new products. The large number of photoproduct bands between 1500 and $1650 \mathrm{~cm}^{-1}$ is striking, especially since only that at $1553 \mathrm{~cm}^{-1}$ can be confidently attributed to $\mathrm{Py}^{+}$based on matrix isolation spectra.

An attempt has been made to assign the unknown absorptions to more complex Py related species. Peak positions in the $\mathrm{Py}: \mathrm{H}_{2} \mathrm{O}$ photolysis experiments are compared to peak positions of 43 pyrene related species from the extensive theoretical database of PAH derivatives (Bauschlicher et al. 2010, WWW. astrochem. org/pahdb). Some groups of molecules indeed do exhibit strong transitions around the peak positions where the absorption maxima are found for the undefined $\mathrm{Py}: \mathrm{H}_{2} \mathrm{O}$ photoproducts. These molecules include $\mathrm{H}, \mathrm{OH}$, and $\mathrm{O}$ added pyrene-based species, such as $\mathrm{C}_{16} \mathrm{H}_{11} \mathrm{O}, \mathrm{C}_{16} \mathrm{H}_{10} \mathrm{O}$, $\mathrm{C}_{16} \mathrm{H}_{12}$, and their cations, in a variety of possible configurations. Although some of these theoretical peak positions overlap with the photoproduct bands, accurate experimental spectral data for these molecules are needed for unambiguous identifications of the reaction products of Py in VUV photolyzed $\mathrm{H}_{2} \mathrm{O}$ ice.

\subsubsection{Benzo[ghi]perylene: $\mathrm{H}_{2} \mathrm{O}$ photoproducts}

As molecular size increases, the number of mid-IR transitions grows and, because of spectral congestion, subtraction of neutral precursor bands becomes increasingly difficult. This makes it hard to obtain clear-cut spectra of the products in the $\mathrm{B}_{\mathrm{ghi}} \mathrm{P}$ photoprocessed ice and hence makes identification of individual bands difficult, if not impossible. As with Ant and Py, the spectra in Fig. 2 and photoproducts listed in Table 3 show that several absorption bands appear which clearly do not have a matrix cation counterband. Unassigned absorptions are found between 1470 and $1540 \mathrm{~cm}^{-1}$ and probably involve CC stretching and $\mathrm{C}-\mathrm{H}$ in plane bending modes. The strong unidentified bands between 1600 and $1640 \mathrm{~cm}^{-1}$ are likely caused by the $\mathrm{C}=\mathrm{O}$ stretching mode of $\mathrm{B}_{\text {ghi }} \mathrm{P}$ ketones formed in the ice. 
Table 3. Band positions of photoproducts appearing upon VUV photolysis of the studied PAHs in $\mathrm{H}_{2} \mathrm{O}$ ice at $15 \mathrm{~K}$ compared to cation absorption band positions and band strengths measured in an argon matrix.

\begin{tabular}{|c|c|c|c|c|}
\hline PAH & $\begin{array}{c}\text { Position }\left(\mathrm{cm}^{-1}\right) \\
\mathrm{H}_{2} \mathrm{O}\end{array}$ & $\begin{array}{c}\text { Position }^{a}\left(\mathrm{~cm}^{-1}\right) \\
\text { Argon }\end{array}$ & Band strength ${ }^{a, b}$ & Ass. ${ }^{c}$ \\
\hline \multirow[t]{21}{*}{$\overline{\text { Ant }}$} & 1155.7 & & & \\
\hline & 1190.5 & 1183.3 & 0.37 & + \\
\hline & & 1188.6 & 18 & + \\
\hline & 1242.7 & & & \\
\hline & 1292.8 & 1290.4 & 1.5 & + \\
\hline & 1326.2 & 1314.6 & 1.5 & + \\
\hline & 1340.5 & 1341 & 26 & + \\
\hline & 1358.3 & 1352.6 & 8.0 & + \\
\hline & & 1364.4 & 1.0 & + \\
\hline & 1412.1 & 1406.1 & 0.39 & + \\
\hline & & 1409.5 & 2.7 & + \\
\hline & 1419.5 & 1418.4 & 22 & + \\
\hline & 1424.7 & 1430.2 & 0.38 & + \\
\hline & 1452.2 & & & \\
\hline & 1459.6 & 1456.5 & 1.9 & + \\
\hline & 1517.9 & & & \\
\hline & 1541.0 & 1539.9 & 3.9 & + \\
\hline & 1567.2 & & & + \\
\hline & 1589.3 & 1586.4 & 3.6 & + \\
\hline & 1603.6 & & & \\
\hline & 1621.1 & & & \\
\hline \multirow[t]{20}{*}{ Py } & 1137.3 & & & \\
\hline & 1182.0 & 1188.7 & 0.56 & + \\
\hline & 1205.2 & & & \\
\hline & 1216.7 & 1216.0 & 1.7 & + \\
\hline & 1232.2 & & & \\
\hline & 1247.6 & $1245.1,1253.7,1255.7$ & 5.6 & + \\
\hline & 1295.4 & & & \\
\hline & 1319.0 & & & \\
\hline & 1337.7 & & & \\
\hline & 1359.0 & $1356.1,1358.4,1361.8$ & 16 & + \\
\hline & 1372.8 & & & \\
\hline & 1393.2 & & & \\
\hline & 1422.2 & 1421.1 & 2.3 & + \\
\hline & 1446.0 & 1440.3 & 1.5 & + \\
\hline & 1484.0 & & & \\
\hline & 1537.5 & & & \\
\hline & 1553.4 & $1550.9,1553.4,1556.0$ & 13 & + \\
\hline & 1567.4 & & & \\
\hline & 1586.4 & & & \\
\hline & 1614.0 & & & \\
\hline \multirow[t]{31}{*}{$\mathrm{B}_{\text {ghi }} \mathrm{P}$} & 1080.2 & & & \\
\hline & 1126.4 & & & \\
\hline & 1146.7 & 1140.2 & 5.5 & + \\
\hline & 1191.0 & & & \\
\hline & 1223.6 & 1216.7 & 0.46 & + \\
\hline & & 1223.4 & 4.1 & + \\
\hline & 1253.1 & & & \\
\hline & 1303.0 & & & \\
\hline & 1322.9 & 1311.9 & 1.9 & + \\
\hline & & 1324.4 & 10 & + \\
\hline & 1339.8 & 1331.9 & 2.3 & + \\
\hline & 1346.2 & & & \\
\hline & 1352.9 & 1350.2 & 2.1 & + \\
\hline & 1366.8 & 1369.0 & 8.6 & + \\
\hline & 1380.3 & & & \\
\hline & 1388.4 & 1388.3 & 0.44 & + \\
\hline & 1406.1 & 1401.3 & 12 & + \\
\hline & & 1408.8 & 0.64 & + \\
\hline & 1433.3 & 1429.4 & 1.3 & + \\
\hline & 1479.7 & & & \\
\hline & 1501.0 & & & \\
\hline & 1510.4 & & & \\
\hline & 1529.7 & & & \\
\hline & 1550.5 & 1538.6 & 0.25 & + \\
\hline & & 1550.1 & 3.1 & + \\
\hline & 1568.0 & & & \\
\hline & 1578.0 & 1578.2 & 14 & + \\
\hline & 1590.2 & & & \\
\hline & 1604.7 & & & \\
\hline & 1617.0 & & & \\
\hline & 1624.3 & & & \\
\hline
\end{tabular}

Notes. ${ }^{(a)}$ Values taken from: Hudgins \& Allamandola (1995a,b). ${ }^{(b)}$ Band strengths are in units of $10^{-18} \mathrm{~cm} /$ molecule. ${ }^{(c)}$ Cation bands are marked with a "+".

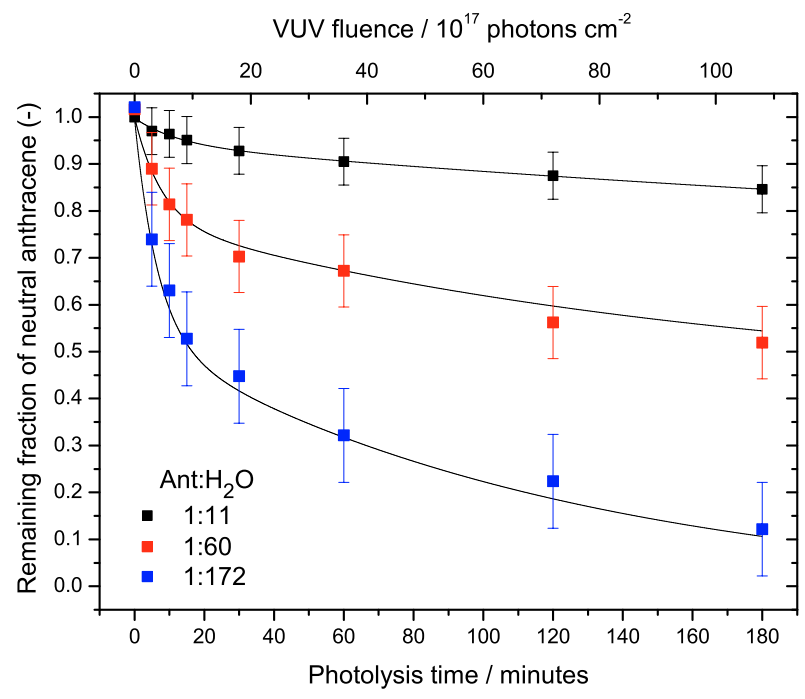

Fig. 3. Neutral anthracene decay as a function of photolysis time (VUV fluence) and concentration for 1:11, 1:60, and 1:172 Ant: $\mathrm{H}_{2} \mathrm{O}$ mixtures at $15 \mathrm{~K}$. Conservative errors are $\pm 5, \pm 7$, and $\pm 10 \%$, respectively, of the initial amount of deposited neutral species. Fits to the data based on a sum of two exponents (solid lines) are indicated as well.

Keeping the types of photoproducts in the Ant and Py ices in mind, it is most likely that $\mathrm{B}_{\text {ghi }} \mathrm{P}$ derivatives containing $\mathrm{H}, \mathrm{O}$, and $\mathrm{OH}$ groups are formed upon photolysis. As for the $\mathrm{Ant}: \mathrm{H}_{2} \mathrm{O}$ and $\mathrm{Py}: \mathrm{H}_{2} \mathrm{O}$ experiments, we cannot unambiguously assign the $\mathrm{B}_{\text {ghi }} \mathrm{P}$ photoproduct absorption bands. The non-volatile residue of a VUV irradiated $\mathrm{B}_{\text {ghi }} \mathrm{P}: \mathrm{H}_{2} \mathrm{O}(<1: 800)$ ice shows the addition of $\mathrm{O}, \mathrm{OH}$ and $\mathrm{H}$ to the neutral parent (Bernstein et al. 1999). Thus, as with the other $\mathrm{PAH}: \mathrm{H}_{2} \mathrm{O}$ systems studied to date, it is likely that many of these new bands in the mid-IR are due to various forms of $\mathrm{B}_{\text {ghi }} \mathrm{P}(-\mathrm{OH})_{n}, \mathrm{~B}_{\text {ghi }} \mathrm{P}(=\mathrm{O})_{n}$, and $\mathrm{B}_{\text {ghi }} \mathrm{P}-\mathrm{H}_{n}$ and possibly their ionized counterparts.

\subsection{Concentration effects and time dependent chemistry}

PAH: $\mathrm{H}_{2} \mathrm{O}$ photolysis experiments have been performed for a set of concentrations ranging from $\sim 1: 11$ to $1: 200$. Here only the Ant: $\mathrm{H}_{2} \mathrm{O}$ experiments are described, but all three investigated PAHs exhibit a similar behavior. Figure 3 shows the decay in the amount of the neutral parent Ant in the ice as a function of photolysis time relative to the amount of the freshly deposited Ant before irradiation. Clearly, Ant loss is far more efficient for lower than for higher PAH concentration. Extrapolating these results, they are in good agreement with recent results that are described in Paper II (Bouwman et al. 2010a, in prep.) for $\mathrm{PAH}: \mathrm{H}_{2} \mathrm{O}$ ices at very low concentration (1: 5000 to 10000), where it was found that all the neutral PAH was consumed at the end of a $4 \mathrm{~h}$ photolysis experiment.

The $15 \mathrm{~K}$ neutral Ant decay data in Fig. 3 are co-plotted with a fit of the form $\Psi=C_{1} \exp \left(-t / \tau_{1}\right)+C_{2} \exp \left(-t / \tau_{2}\right)$. Fitting the experimental data required a sum of two exponentials. This indicates that more than one process is responsible for the neutral Ant loss. This is consistent with the optical work reported by Bouwman et al. (2010b, in prep.) in which two photochemical reaction networks were described, one for $\mathrm{PAH}$ cation formation, the other involving $\mathrm{H}, \mathrm{O}$, and $\mathrm{OH} \mathrm{PAH}$ addition reactions.

The time dependent PAH cation and other photoproduct signals are also studied as a function of photolysis time (VUV dose). For the lowest concentration $\mathrm{Py}: \mathrm{H}_{2} \mathrm{O}$ ice in our sample (1:200), the time dependent behavior of the photoproduct 


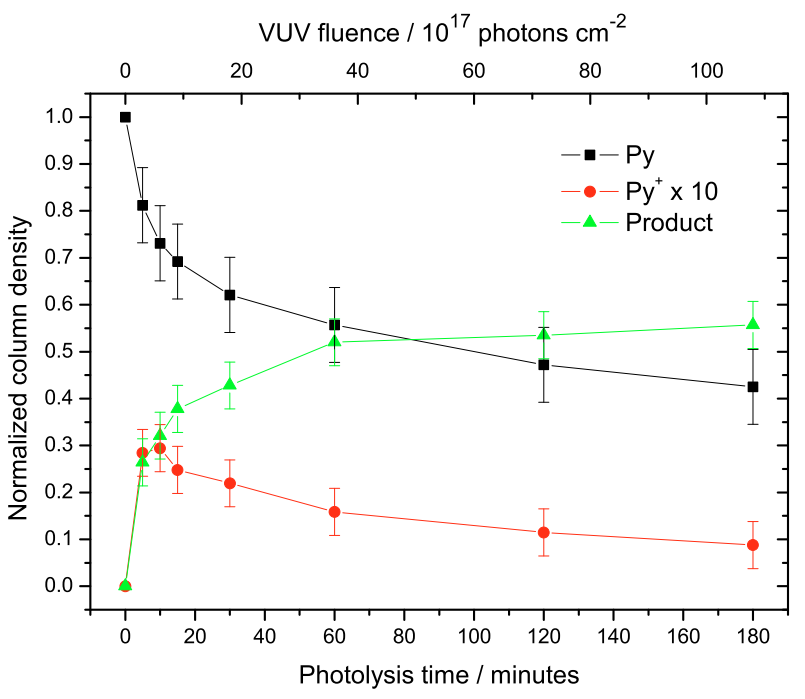

Fig. 4. Evolution of $\mathrm{Py}, \mathrm{Py}^{+}$and a single Py photoproduct for a 1:200 Py: $\mathrm{H}_{2} \mathrm{O}$ ice at $15 \mathrm{~K}$ as a function of photolysis time (VUV fluence). Photoproduct species are tracked using the 1359 and $1553 \mathrm{~cm}^{-1} \mathrm{Py}^{+}$ and $1567 \mathrm{~cm}^{-1}$ Py photoproduct bands.

bands is compared to the optical results presented in Paper II. To this end, the behavior of the cation is traced as a function of VUV time by integrating two of the most isolated prominent $\mathrm{Py}^{+}$ absorption bands in the spectra, located at 1359 and $1554 \mathrm{~cm}^{-1}$. Figure 4 shows the time evolution of the column density of the $\mathrm{Py}^{+}$species derived from these bands (multiplied by a factor of 10 and normalized to the initial amount of neutral Py to facilitate the display) together with the time evolution of the relative amount of neutral Py in the ice based on the subtraction factor, $Y$. The photolytic behavior of the integrated absorption of the strongest undefined photoproduct band at $1567 \mathrm{~cm}^{-1}$ (multiplied by a factor of 100 to facilitate the display) is also shown. Because no information is available on the band strength of this species, we cannot convert this integrated absorbance into a column density relative to the amount of deposited neutral PAH. The $\mathrm{Py}^{+}$bands and $1567 \mathrm{~cm}^{-1}$ photoproduct band show a different time dependence and clearly do not correlate. While the integrated absorbance of $\mathrm{Py}^{+}$reaches a maximum after some $10 \mathrm{~min}$ and then declines, the photoproduct signal grows and levels off towards the end of the experiment.

The error in the $\mathrm{Py}^{+}$column density is reduced by taking the average column density based on the two strongest cation absorptions located at 1359 and $1554 \mathrm{~cm}^{-1}$. We estimate the error in the relative $\mathrm{Py}^{+}$abundance to be $\pm 5 \%$ of the deposited amount of neutral Py and, thus, the shape of the time dependence curve is well defined. The error in the absolute number, however, is much larger because the argon band strength values from Table 3 have to be used for the analysis and because of ill-defined baselines caused by spectral congestion. Therefore, the error in the absolute amount of $\mathrm{Py}^{+}$produced can be quite high. For this reason, reliable quantitative time dependent data can only be obtained in the optical spectral regime, where cation absorptions are isolated and spectra are taken on a much shorter time scale. This is described in Paper II of this series (Bouwman et al. 2010a, in prep.). The error in the absolute number of neutral Py molecules consumed, on the other hand, is low $( \pm 7 \%)$. Since no information is available on the band strength of the $1567 \mathrm{~cm}^{-1}$ unidentified photoproduct absorption band, no quantitative information can be obtained on the formation of the species responsible for this band.
Using the PAH cation in Ar band strengths values, it is also possible to derive $F_{\text {frac }}$, the first order estimate of the fraction of the used-up neutral PAH that is converted into cation species versus other photoproducts. The amount of deposited neutral, $N_{\mathrm{PAH}}$, is known from concentration measurements (Eqs. (1) and (2)) and the amount of consumed neutral is given by $(1-Y) N_{\mathrm{PAH}}$. The cation column density, $N_{\mathrm{PAH}^{+}}$, is calculated with Eq. (2) and the band strength values reported in Table 3 . The difference between the two, $(1-Y) N_{\mathrm{PAH}}-N_{\mathrm{PAH}}^{+}$, makes up the photoproduct column density. The fraction of consumed neutral PAH molecules converted into $\mathrm{PAH}^{+}$is given by:

$F_{\text {frac }}=\frac{N_{\mathrm{PAH}^{+}}}{\left[(1-Y) N_{\mathrm{PAH}}\right]}$.

Values $F_{\text {frac }}$ have been derived for different conditions for the three PAHs studied here. After 5 min of VUV photolysis of the $\mathrm{Py}: \mathrm{H}_{2} \mathrm{O}(1: 200)$ mixture, about $20 \%$ of the neutral pyrene is used up and of this fraction roughly $15 \%$ is converted into $\mathrm{Py}^{+}$and $85 \%$ in other charged and/or neutral photoproducts. The $\mathrm{Py}^{+}$ absorption peaks at about 10 min of VUV photolysis, a value that is also found in the optical study for much lower PAH concentrations (1:5000-1:10000). A mid-IR experiment on an ice sample with a higher Py concentration (1:60) results in an even lower $F_{\text {frac }}$ value of about 0.05 , a trend that suggests that ionization is more important in low concentration ices. Similar trends are found for low concentration mixtures of $\mathrm{B}_{\text {ghi }} \mathrm{P}-\mathrm{a}(1: 160)$ mixture gives $F_{\text {frac }} \approx 0.20-$ and Ant - a $(1: 172)$ mixture gives $F_{\text {frac }} \approx 0.10$ - after 5 min of VUV photolysis.

The quantitative analysis by Bouwman et al. (2010b) points out that there is a $\mathrm{Py}^{+}+\mathrm{e}^{-}$recombination channel. It is argued that the recombination reaction is most likely a local process, i.e., the electron released after ionization remains in the vicinity of its parent Py molecule. Putting this in perspective with the data presented here, this means that the recombination channel can well be more efficient in ices of higher concentration; the chance of recombination with an electron released from a neighboring Py molecule is larger. In the higher concentration experiments presented here, not all the neutral PAH is used up. Presumably some of the deposited PAHs are shielded from VUV irradiation and therefore not ionized. This may also explain the difference between the ionized fraction in low versus high concentration ices. Furthermore, as discussed before, ionization seems to be less efficient at high concentration ices, because chemical reactions between PAHs and radical species likely dominate the loss of the neutral species.

In summary, all PAH molecules trapped in $\mathrm{H}_{2} \mathrm{O}$ ice exhibit a similar photoprocessing behavior. Ionization is more important in low concentration ices. However, after $5 \mathrm{~min}$ of VUV photolysis, most of the destroyed neutral species are converted into different PAH based photoproducts other than the cation. The concentration of the ice sample has a large influence on the efficiency of the chemical reactions. PAHs in lower concentration ices are used up faster and more efficiently, whereas in higher concentration ices, the PAH consumption is far less efficient. Although no mid-IR VUV photolysis measurements have been performed on coronene: $\mathrm{H}_{2} \mathrm{O}$ ice mixtures, the nearUV/VIS study presented in Paper II of this series (Bouwman et al. 2010a, in prep.) shows that also coronene exhibits a similar behavior.

\subsection{Ionization efficiency in $\mathrm{CO}$ ice}

A control experiment has been performed on a Py:CO ice sample at $15 \mathrm{~K}$ to investigate the ionization efficiency of PAHs upon 
photolysis in a CO matrix. After a short photolysis time (150 s), the ice exhibits weak absorptions at 1861 and $1090 \mathrm{~cm}^{-1}$. These mid-IR absorption bands were previously assigned to the HCO radical by Milligan \& Jacox (1969). This observation is consistent with experiments performed by Bouwman et al. (2010b), where the electronic HCO signature is found in the 500 to $660 \mathrm{~nm}$ spectral range. There, it is also found that, in a CO matrix, the Py ionization efficiency is close to zero, unless a certain level of $\mathrm{H}_{2} \mathrm{O}$ contamination in the $\mathrm{CO}$ matrix is reached. In the mid-IR experiment performed here, VUV photolysis of Py in a $\mathrm{CO}$ matrix indeed does not show any sign of pyrene ionization, but also does not show any other $\mathrm{PAH}: \mathrm{H}_{2} \mathrm{O}$ photoproduct bands. We do confirm the low ionization efficiency and the appearance of small $\mathrm{HCO}^{\circ}$ absorptions in a nearly pure $\mathrm{CO}$ ice, but no absorptions caused by $\mathrm{PyH}^{-}$species, as in the optical study, are observed. The fact that PAH absorption band strengths typical of electronic transitions are 100 times stronger than those for vibrational transitions, and that the level of $\mathrm{H}_{2} \mathrm{O}$ contamination, i.e. the source of $\mathrm{H}$-atoms for the reaction $\mathrm{H}^{-}+\mathrm{CO} \rightarrow \mathrm{HCO}$, is lower in the experiments described here, probably explains why the $\mathrm{PyH}^{\circ}$ mid IR absorption bands were not detected. The important conclusion that follows from this control experiment is that $\mathrm{H}_{2} \mathrm{O}$ catalyzes the ionization process. This is also consistent with the observation that ionization seems to be more efficient in low concentration $\mathrm{PAH}: \mathrm{H}_{2} \mathrm{O}$ ices.

\subsection{Temperature effects}

VUV photolysis experiments on $\mathrm{PAH}: \mathrm{H}_{2} \mathrm{O}$ samples $(\sim 1: 60)$ were also conducted at a higher temperature $(125 \mathrm{~K})$. Consistent with the behavior reported in the optical studies (Bouwman et al. 2010b), we find that the neutral PAH loss is still efficient, while the ionization channel is strongly suppressed. The less efficient formation of the cation can point to a lower rate of ionization, but it is also possible that the recombination channel becomes dominant at higher temperatures. The result is that, at higher temperatures, the parent PAHs are more efficiently converted into species other than the PAH cation.

In the high temperature $\mathrm{Py}: \mathrm{H}_{2} \mathrm{O}$ experiment, for example, some pronounced vibrational bands appear immediately upon VUV photolysis. These bands, located at 1137.8, 1216.7, $1386.1 \mathrm{~cm}^{-1}$ and a broad feature consisting of bands at 1553.5 , 1566.1 , and $1583.1 \mathrm{~cm}^{-1}$, become strongest after $5 \mathrm{~min}$ of photolysis and then subside. Only the bands at 1216.7 and $1553.5 \mathrm{~cm}^{-1}$ are at positions of $\mathrm{Py}^{+}$absorptions. The remaining bands are also apparent in the low temperature spectra, but shifted by up to $3 \mathrm{~cm}^{-1}$ and, in the absence of many of the other bands, seem to be more pronounced in the high temperature photolysis dataset.

For the PAH: $\mathrm{H}_{2} \mathrm{O}$ ices irradiated at high temperatures there is a very broad overlapping substructure superimposed on the baseline of their mid-IR spectra. This is presumably caused by blended photoproducts and possibly PAH aggregates. Together with the knowledge that more complex species have been detected in other experiments (Bernstein et al. 1999, 2002; Ashbourn et al. 2007), we conclude that predominantly a mixture of $\mathrm{PAH}-\mathrm{X}_{n}$ species, with $\mathrm{X}$ being $\mathrm{H}$, O, or $\mathrm{OH}$, may have been formed and that only one or a few chemical reaction channels dominate, resulting in the observed bands.

Ices at a temperature of $125 \mathrm{~K}$ are known to be of different structure than ices at low temperature (Jenniskens \& Blake 1994). This structural difference - amorphous at $15 \mathrm{~K}$ vs. cubic crystalline at $125 \mathrm{~K}$ - may explain the different photochemical behavior. However, Bouwman et al. (2010b) investigated the

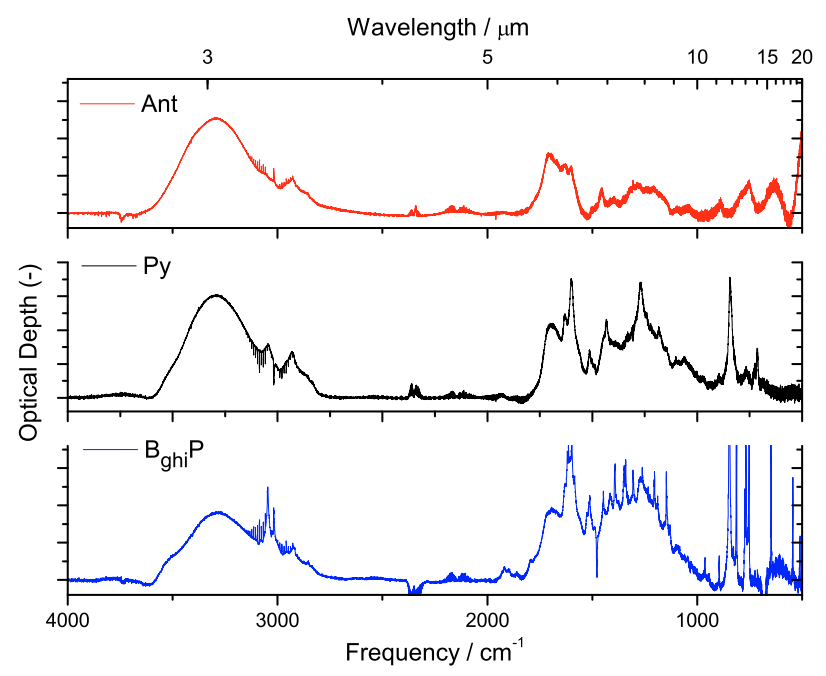

Fig. 5. Overview of the room temperature spectra of the residues accumulated during the photolysis of Ant, $\mathrm{Py}$, and $\mathrm{B}_{\text {ghi }} \mathrm{P}$ containing $\mathrm{H}_{2} \mathrm{O}$ ices.

influence of the ice structure on the photoionization and found that ices annealed at $125 \mathrm{~K}$ and subsequently cooled down to $25 \mathrm{~K}$ exhibit similar ionization behavior as those grown and photolyzed at $25 \mathrm{~K}$. Hence, they ascribed the different behavior at high temperatures to the larger mobility of radical species in the ice. The experiments presented here, point out a similar behavior.

\section{The non-volatile residue}

Figure 5 shows the 4000 to $500 \mathrm{~cm}^{-1}$ room temperature spectra of the non-volatile residues produced by the photolysis of the three PAH: $\mathrm{H}_{2} \mathrm{O}$ ices considered here. The spectra are measured as described in Sect. 2 and provide additional information on the photoproducts which have accumulated over a series of experiments for a particular PAH. These residues - complex mixtures of the non-volatile photoproducts, may also contain some of the parent $\mathrm{PAH}$ as well as some trapped $\mathrm{H}_{2} \mathrm{O}$ or $\mathrm{H}_{2} \mathrm{O}$ that accreted during the cooling of the sample window. Because the $\mathrm{H}_{2} \mathrm{O}$ absorption bands in these spectra are much smaller than in the experiments on PAH: $\mathrm{H}_{2} \mathrm{O}$ ice mixtures, the spectra can be investigated over the full range from 4000 to $500 \mathrm{~cm}^{-1}$. In the ROI, the spectra show continuous, undulating absorptions from about 1750 to $1130 \mathrm{~cm}^{-1}$ with several distinct features superposed. Additional spectral features are found between 3750 and $2750 \mathrm{~cm}^{-1}$. The chemical subgroups indicated by these features are consistent with the addition of $\mathrm{O}, \mathrm{H}$, and $\mathrm{OH}$ to the parent $\mathrm{PAH}$.

The aromatic-rich nature of these residues makes their spectra qualitatively different from the 13 residue spectra previously analyzed to compare with the spectrum of the diffuse interstellar medium (Pendleton \& Allamandola 2002). While it is impossible to identify the molecules comprising the residues using infrared spectroscopy, it is possible to characterize the species and subgroups present by chemical type (i.e. aliphatic versus aromatic hydrocarbons, carbonyl vs. alcohol carbon-oxygen chemical bonds, etc.). The following analysis utilizes the characteristic group frequencies as well as relative and intrinsic band strengths as described in (Bellamy 1960; Silverstein \& Bassler 1967; Wexler 1967). The prominent features in these spectra are discussed systematically from higher to lower frequency.

- The $3300 \mathrm{~cm}^{-1}, O-H$ stretch: a large part of this band can be ascribed to $\mathrm{H}_{2} \mathrm{O}$ accretion to the cold sample, since the 
residue spectra are based on background spectra taken of a cold sample window. However, the weak sideband near $3550 \mathrm{~cm}^{-1}$ points to the $\mathrm{O}-\mathrm{H}$ stretching mode in phenols and, thus, the presence of aromatic alcohols in the residues.

- The $3060 \mathrm{~cm}^{-1}$ aromatic $C-H$ stretch: the next prominent band, peaking near $3060 \mathrm{~cm}^{-1}$, is due to the aromatic $\mathrm{C}-\mathrm{H}$ stretch belonging to either the parent $\mathrm{PAH}$ or $\mathrm{PAH}$ photoproducts.

- The 2990-2850 $\mathrm{cm}^{-1}$ aliphatic $C-H$ stretch: the addition of $\mathrm{H}$ to the aromatic parent forms a new type of functional group, which is evident from the broad aliphatic $\mathrm{C}-\mathrm{H}$ stretch feature between about 2850 and $2990 \mathrm{~cm}^{-1}$. The two subpeaks at about 2925 and $2860 \mathrm{~cm}^{-1}$ are characteristic of methylene $\left(-\mathrm{CH}_{2}-\right)$ groups, showing that the major $\mathrm{H}$-addition channel proceeds by addition, not ring opening. If ring opening had been an important channel, bands due to the $\mathrm{C}-\mathrm{H}$ stretches of methyl $\left(-\mathrm{CH}_{3}\right)$ groups near 2960 and $2870 \mathrm{~cm}^{-1}$ would have been expected. The assignment to methylene groups is further supported by the prominent band near $1450-1460 \mathrm{~cm}^{-1}$ in the lower two spectra shown in Fig. 5. A band in this region indicates the $-\mathrm{CH}_{2}-$ scissoring mode in cyclic saturated compounds such as cyclohexane and cyclopentane. The spectrum of $\mathrm{B}_{\text {ghi }} \mathrm{P}$ is consistent with this analysis, but the bands are weaker. Given that the intrinsic strength of the aromatic $\mathrm{C}-\mathrm{H}$ stretch is 10 times weaker than the intrinsic strength of the aliphatic $\mathrm{C}-\mathrm{H}$ stretch per $\mathrm{C}-\mathrm{H}$ (Wexler 1967), the increasing ratio of the aromatic band intensity to the aliphatic band intensity with PAH size indicates that $\mathrm{H}$ addition becomes less effective as the PAH size increases.

- The $1700 \mathrm{~cm}^{-1}$ carbonyl $\mathrm{C}=\mathrm{O}$ stretch: as with the $\mathrm{O}-\mathrm{H}$ stretching band near $3 \mu \mathrm{m}$, some of this band may be attributed to the bending mode of $\mathrm{H}_{2} \mathrm{O}$ molecules frozen onto the cold sample window. However, it is likely that part of this band is caused by the $\mathrm{C}=\mathrm{O}$ stretch in carbonyl groups. In this case, quinone-like structures would be expected with the double bond to $\mathrm{O}$ participating in the conjugation of the molecule as a whole.

- The band at $1625 \mathrm{~cm}^{-1}$ : a distinct feature is evident at this frequency in all three spectra. The value is low for isolated carbonyls, but is characteristic for the carbonyl $\mathrm{C}=\mathrm{O}$ stretch in molecules with intramolecular hydrogen bonding with an $\mathrm{OH}$ group.

- The $1600 \mathrm{~cm}^{-1}$ aromatic CC stretch: a well defined, but generally weak band centered near $1600 \mathrm{~cm}^{-1}$ is characteristic of the CC skeletal stretch in aromatic molecules. The prominence of this band in all three residue spectra shows, not surprisingly, that they are primarily aromatic in nature.

- The bands between 1520 and $1500 \mathrm{~cm}^{-1}$ : several features in this region become more prominent with parent PAH size. We are unable to attribute these bands to specific molecular vibrations.

- The 1450 and $1440 \mathrm{~cm}^{-1}-\mathrm{CH}_{2}$ - scissoring vibration: this band has been discussed in the paragraph describing the aliphatic $\mathrm{C}-\mathrm{H}$ vibrations above.

- The $1260 \mathrm{~cm}^{-1}$ band in the pyrene photoproduct: while this prominent band falls in the $1300-1000 \mathrm{~cm}^{-1}$ region which is characteristic of aromatic $\mathrm{C}-\mathrm{H}$ in-plane bending vibrations, other likely compounds also absorb in this region. For example, the $\mathrm{C}-\mathrm{O}$ stretch in aromatic alcohols has a strong band between 1260 and $1180 \mathrm{~cm}^{-1}$.

- The 900 to $500 \mathrm{~cm}^{-1}$ aromatic $C-H$ out-of-plane bends: this region encompasses the very strong $\mathrm{C}-\mathrm{H}$ out of plane vibrations which are diagnostic of substitution patterns on the
Table 4. Molecules, their vibrational modes and solid state absorption band positions possibly contributing to the $5-8 \mu \mathrm{m}$ ice absorption complex towards low- and high-mass embedded objects.

\begin{tabular}{|c|c|c|c|c|}
\hline Molecule & Mode & $\lambda(\mu \mathrm{m})$ & $v\left(\mathrm{~cm}^{-1}\right)$ & Ref. \\
\hline \multirow[t]{2}{*}{$\mathrm{H}_{2} \mathrm{O}$} & $\mathrm{H}-\mathrm{O}-\mathrm{H}$ bend & $5.4-9$ & $1852-1111$ & 1 \\
\hline & Libr. overtone & & & 1 \\
\hline $\mathrm{H}_{2} \mathrm{CO}$ & $\mathrm{C}=\mathrm{O}$ stretch & 5.83 & 1715 & 2 \\
\hline $\mathrm{CH}_{3} \mathrm{HCO}$ & $\mathrm{C}=\mathrm{O}$ stretch & 5.83 & 1715 & 3 \\
\hline $\mathrm{HCOOH}$ & $\mathrm{C}=\mathrm{O}$ stretch & 5.85 & 1709 & 3,4 \\
\hline $\mathrm{NH}_{3}$ & $\mathrm{H}-\mathrm{N}-\mathrm{H}$ bend & 6.16 & 1623 & 5 \\
\hline PAH? & CC stretch & 6.20 & 1613 & 6 \\
\hline $\mathrm{HCOO}^{-}$ & $\mathrm{C}=\mathrm{O}$ stretch & 6.33 & 1580 & 3 \\
\hline $\mathrm{H}_{2} \mathrm{CO}$ & $\mathrm{H}-\mathrm{C}-\mathrm{H}$ bend & 6.68 & 1497 & 2 \\
\hline $\mathrm{NH}_{4}^{+}$ & Deformation & 6.85 & 1460 & 7 \\
\hline $\mathrm{HCOOH}$ & $\mathrm{C}-\mathrm{H}$ stretch & 7.25 & 1379 & 3,4 \\
\hline $\mathrm{HCOO}^{-}$ & $\mathrm{C}-\mathrm{H}$ deform. & 7.40 & 1351 & 3 \\
\hline $\mathrm{SO}_{2}$ & Asymm. stretch & 7.58 & 1319 & 8 \\
\hline $\mathrm{CH}_{4}$ & Deformation & 7.68 & 1302 & 9 \\
\hline
\end{tabular}

References. (1) D'Hendecourt \& Allamandola (1986); (2) Schutte et al. (1993); (3) Schutte et al. (1999); (4) Bisschop et al. (2007); (5) Kerkhof et al. (1999); (6) Keane et al. (2001), Kerkhof et al. (1999) ; (7) Schutte \& Khanna (2003); (8) Boogert et al. (1997); (9) Boogert et al. (1996).

edge rings. In this case, these bands serve primarily as an indication of the presence of aromatic compounds.

All the pure PAHs under investigation here exhibit strong fluorescence upon excitation with a hand-held UV lamp. It is noteworthy, that after performing the experiments, the residues do not exhibit any fluorescence. This is consistent with the residues being processed PAHs with a different chemical identity.

\section{Astrophysical implications}

The 5-8 $\mu \mathrm{m}$ spectra of embedded low- and high-mass objects are generally dominated by two strong bands originating from interstellar ice, one centered near $6.0 \mu \mathrm{m}$ and primarily attributed to the $\mathrm{H}_{2} \mathrm{O}$ bending mode, and the other near $6.8 \mu \mathrm{m}$. Close inspection of the spectra of many different molecular clouds shows that, while features near 6.0 and $6.8 \mu \mathrm{m}$ are nearly always present, band positions, profiles, and relative strengths of other features vary somewhat from one object to another, revealing changes in ice composition and structure (e.g. Keane et al. 2001; Keane 2001; Gibb \& Whittet 2002; Schutte \& Khanna 2003; Boogert \& Ehrenfreund 2004; Boogert et al. 2008). Besides the two dominant absorptions, signals are also found from other species that absorb in the 5-8 $\mu \mathrm{m}$ region. An overview of absorptions by molecular species in this wavelength region is given in Table 4. The knowledge of interstellar ice composition and chemistry is based on over twenty five years of dedicated studies on laboratory ice analogs to interpret these observations (see references mentioned above and Ehrenfreund \& Charnley 2000; van Dishoeck 2004, and references therein). However, to date, such studies considering PAHs in ices and their contribution to the 5-8 $\mu \mathrm{m}$ absorption complex are lacking. Here, we discuss the possible contribution of PAHs in ices to the spectra of both high- and low-mass objects, using the laboratory data presented in the previous sections.

\subsection{High-mass protostars}

Figure 6 shows the $\sim 5.3-8.7 \mu \mathrm{m}\left(1900-1150 \mathrm{~cm}^{-1}\right)$ ISO SWS spectrum towards the high-mass protostar W33A (based on data 


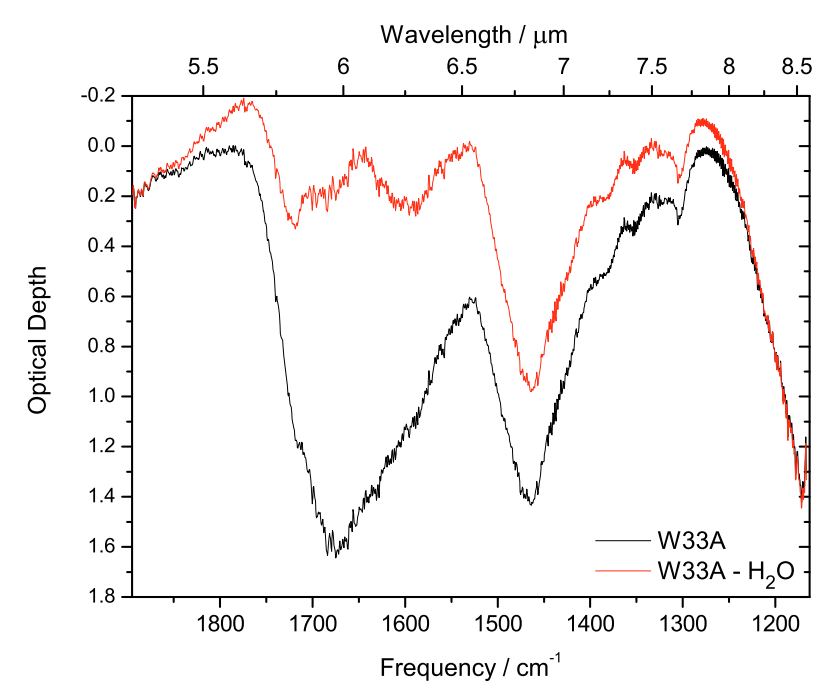

Fig. 6. The 5.3 to $8.7 \mu \mathrm{m}$ ISO SWS spectrum of the high-mass protostar W33A plotted in optical depth together with the spectrum obtained after subtraction of the $\mathrm{H}_{2} \mathrm{O}$ bending and librational overtone modes. The figure is adapted, with permission, from Keane et al. (2001).

from Keane et al. 2001) and the residual that remains after subtracting the $\mathrm{H}_{2} \mathrm{O}$ bending and librational overtone bands in a manner similar to that described in Sect. 2. Based on a sample of five ISO spectra towards high-mass protostars, Keane et al. (2001) attributed the bulk of the $6.0 \mu \mathrm{m}$ ice band to amorphous $\mathrm{H}_{2} \mathrm{O}$ ice, with additional absorptions on the short wavelength wing near $5.8 \mu \mathrm{m}$ and on the long wavelength wing near $6.2 \mu \mathrm{m}$. They assigned the short wavelength absorption at $5.83 \mu \mathrm{m}$ to the carbonyl $\mathrm{C}=\mathrm{O}$ stretch in formaldehyde and related species based on laboratory studies and suggested that the $6 \mu \mathrm{m}$ long wavelength absorption at $6.2 \mu \mathrm{m}$ can be due to the CC stretch of aromatic structures in PAHs or amorphous carbon particles. Keane et al. (2001) also showed that the $6.85 \mu \mathrm{m}$ band is comprised of two components, one centered near $6.75 \mu \mathrm{m}$, and the other at $6.95 \mu \mathrm{m}$, but they did not assign possible band carriers. Noteworthy in Fig. 6 are also the weak undulating features between $\sim 7.2$ and $7.9 \mu \mathrm{m}$. Assignments of these absorption features are discussed in Schutte \& Khanna (2003).

\subsection{Low-mass protostars}

Figure 7 shows the $\sim 5.3-8.1 \mu \mathrm{m}\left(1900-1234 \mathrm{~cm}^{-1}\right)$ spectrum of the low-mass YSO RNO 91, reproduced from Boogert et al. (2008) and the spectrum of the residuals that remain after subtracting the contribution by the water bending mode. In this more recent, extensive spectroscopic study of the 5-8 $\mu \mathrm{m}$ region of 41 low luminosity, low-mass protostars measured with the Spitzer telescope, Boogert et al. (2008) showed that, once the contribution from $\mathrm{H}_{2} \mathrm{O}$ ice is removed, the $5-8 \mu \mathrm{m}$ residual spectrum can be split into five components (C1-C5). The large sample of objects permitted Boogert et al. to extract rough band profiles, although not uniquely assignable to specific band carriers, and to determine source to source variations for all five components. The positions of the $\mathrm{C} 1$ through $\mathrm{C} 4$ components are similar to those described in Keane et al. (2001) and part of these bands can be attributed to the species mentioned in Table 4. C5, a very broad, underlying component that stretches from about 1725 to $1250 \mathrm{~cm}^{-1}(5.8-8 \mu \mathrm{m})$ cannot be explained by any of these species and is most likely a blend of more than one species. As

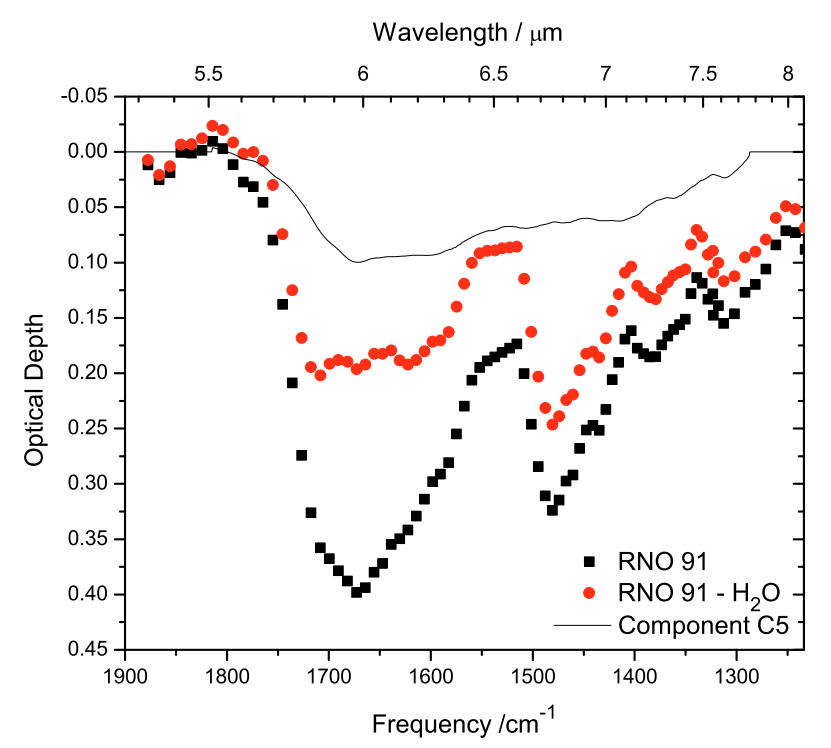

Fig. 7. The 5.3 to $8.1 \mu \mathrm{m}$ Spitzer spectrum of the low-mass YSO RNO 91 plotted in optical depth together with the spectrum obtained after subtraction of the $\mathrm{H}_{2} \mathrm{O}$ bending, and librational overtone modes. The C5 complex absorption as described by Boogert et al. (2008) is also indicated (solid line). The figure is adapted, with permission, from Boogert et al. (2008).

with the spectrum of W33A, RNO 91 also shows several weaker features between 7.2 and $7.9 \mu \mathrm{m}$.

\subsection{PAH contributions to the 5-8 $\mu \mathrm{m}$ absorption}

Here, we discuss the possible contribution that interstellar ices containing PAHs and their photoproducts could make to the spectra of molecular clouds in the $6.1-8.3 \mu \mathrm{m}$ $\left(1650-1200 \mathrm{~cm}^{-1}\right)$ region. The comparison is restricted to the three PAHs studied here. These three PAHs, Ant in particular, are on the low end of the PAH size distribution expected in space. As a consequence, the relative intensities of the modes are different than those expected for larger PAHs in the interstellar case. Infrared bands which result from the $\mathrm{C}-\mathrm{H}$ functional group are expected to be less intense in space with respect to modes resulting from aromatic $\mathrm{CC}$ stretches, since astronomical PAHs are large and contain relatively more aromatic $\mathrm{CC}$ bonds than $\mathrm{CH}$ bonds. Figure 8 shows the photoproduct bands that appear after $180 \mathrm{~min}$ of VUV photolysis of the PAHs considered here in $\mathrm{H}_{2} \mathrm{O}$ ice. All VUV processed $\mathrm{PAH}: \mathrm{H}_{2} \mathrm{O}$ mixtures under investigation exhibit bands clustered around $1600 \mathrm{~cm}^{-1}$. The band at $6.2 \mu \mathrm{m}$, observed towards both low- and high-mass sources and also shown in Fig. 8, could well be caused by a superposition of many different large PAH and PAH photoproduct absorption bands, or organic refractory material as discussed in Sect. 5. Additional minor PAH absorptions throughout the 6-10 $\mu \mathrm{m}$ spectrum can be (partly) responsible for the underlying C5 complex absorption which is also indicated in Fig. 5 as well as the weak undulating structure between 7.2 and $7.9 \mu \mathrm{m}$.

The observational data also permit one to put crude limits on the column densities of PAHs condensed in interstellar ice. Assuming that the $6.2 \mu \mathrm{m}$ feature in the residual spectra shown in Fig. 8 are due primarily to the aromatic CC stretching vibration in PAHs and closely related aromatic material frozen in $\mathrm{H}_{2} \mathrm{O}$-rich interstellar ice, one can estimate their column density $\left(N_{\text {PAH }}\right)$ with Eq. (2). The integrated optical depths of the component are $\sim 16 \mathrm{~cm}^{-1}$ for $\mathrm{W} 33 \mathrm{~A}$ and $\sim 1.3 \mathrm{~cm}^{-1}$ for 


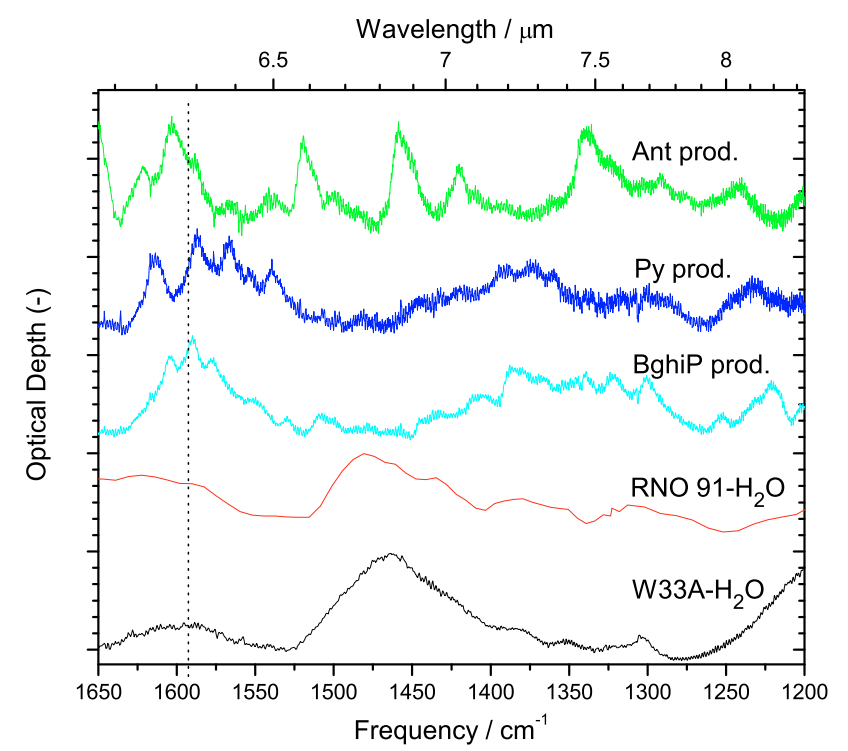

Fig. 8. The $6.1-8.3 \mu \mathrm{m}\left(1650 \mathrm{~cm}^{-1}-1200 \mathrm{~cm}^{-1}\right)$ region of the spectra of W33A and RNO 91 after subtraction of the $\mathrm{H}_{2} \mathrm{O}$ bending and librational overtone contributions plotted in absorbance compared to the spectra of the products after 180 min of $\mathrm{PAH}: \mathrm{H}_{2} \mathrm{O}$ ice photolysis. The dotted line guides the eye to the $\sim 6.2 \mu \mathrm{m}$ ice absorption and main $\mathrm{PAH}: \mathrm{H}_{2} \mathrm{O}$ ice photoproduct bands.

RNO 91. The experimental data indicate that a certain number of neutral PAH species is converted into PAH photoproduct species, as indicated by $(1-Y) N_{\text {neutral }}$, where $N_{\text {neutral }}$ is the column density of deposited neutral molecules. This allows us to calculate an average band strength for the species responsible for the absorption band around $6.2 \mu \mathrm{m}$ with Eq. (2). The resulting average band strength $\left(A_{\text {prod }}\right)$ for the formed PAH products is $1.2 \times 10^{-17} \mathrm{~cm}$ molecule ${ }^{-1}$. With these assumptions, the column density of neutral PAHs and PAH photoproducts frozen in $\mathrm{H}_{2} \mathrm{O}$ is $1.3 \times 10^{18}$ molecules $\mathrm{cm}^{-2}$ for the high-mass object (W33A) and $7.6 \times 10^{16}$ molecules $\mathrm{cm}^{-2}$ for the low-mass object (RNO 91). Given that the column densitiy of $\mathrm{H}_{2} \mathrm{O}$ ice along the line of sight to these objects is $4 \times 10^{19}$ molecules $/ \mathrm{cm}^{2}$ and $4.3 \times 10^{18}$ molecules $/ \mathrm{cm}^{2}$ (Keane et al. 2001; Boogert et al. 2008), respectively, this implies $\mathrm{PAH}$ and $\mathrm{PAH}$ photoproduct abundances between 2-3\% with respect to water. This concentration range is reasonable given the $\mathrm{PAH}$ abundances derived from mid-IR emission features (Puget \& Leger 1989; Allamandola et al. 1989).

\section{Conclusions}

The manuscript describes mid-IR absorption spectroscopy of PAH: $\mathrm{H}_{2} \mathrm{O}$ ices, their VUV induced photochemistry and photoproducts. The main conclusions of this manuscript are summarized below.

1. Band positions, FWHMs, and relative intensities of anthracene, pyrene and benzo[ghi]perylene in $\mathrm{H}_{2} \mathrm{O}$ ice in the $1650-1000 \mathrm{~cm}^{-1}$ spectral window are compared to their matrix isolation data. Additionally, band strengths are derived for these species isolated in an astrophysically relevant $\mathrm{H}_{2} \mathrm{O}$ ice at $15 \mathrm{~K}$.

2. VUV photolysis of PAH containing $\mathrm{H}_{2} \mathrm{O}$ ice causes the embedded PAH to ionize and react with $\mathrm{H}_{2} \mathrm{O}$ photoproducts. The band positions of $\mathrm{PAH}$ cations trapped in $\mathrm{H}_{2} \mathrm{O}$ ice are measured and compared to $\mathrm{PAH}$ cation values from previous argon matrix isolation studies. Additionally, peak po- sitions of $\mathrm{PAH}: \mathrm{H}_{2} \mathrm{O}$ photoproducts other than the cation are determined and tentatively assigned to $\mathrm{PAH}-\mathrm{X}_{n}$ species, with $\mathrm{X}$ being $\mathrm{O}, \mathrm{H}$ or $\mathrm{OH}$.

3. The VUV induced photochemistry of the PAH pyrene in a $\mathrm{CO}$ ice was also studied. In this case, PAH ionization is inefficient compared to a VUV irradiated $\mathrm{PAH}: \mathrm{H}_{2} \mathrm{O}$ ice and seems to depend on the presence of trace amounts of $\mathrm{H}_{2} \mathrm{O}$.

4. The photochemistry is also tracked as a function of PAH: $\mathrm{H}_{2} \mathrm{O}$ ice concentration for PAH: $\mathrm{H}_{2} \mathrm{O}$ ratios $\sim 1: 10$ to 1:200. The fraction of neutral molecules converted into the cation is found to be larger in ices of lower concentration, consistent with the previous conclusion, whereas the fraction of neutral PAHs converted into photoproduct species other than the PAH cation is larger in ices of higher PAH concentration.

5. The PAH: $\mathrm{H}_{2} \mathrm{O}$ ice photochemistry is tracked as a function of VUV fluence by monitoring the integrated absorbances of the parent $\mathrm{PAH}$ and $\mathrm{PAH}$ photoproduct bands periodically during photolysis for several hours. In all cases, the PAH cation bands peak after some 5 to $10 \mathrm{~min}$ and then slowly decline, while other photoproduct bands continue to grow steadily and starts to level off after about an hour of irradiation.

6. The ice photochemistry is monitored for two ice temperatures, 15 and $125 \mathrm{~K}$. PAH cation formation is important and dominates the first few minutes in the low temperature case. However, ionization is far less efficient in the $125 \mathrm{~K}$ ice while the loss of the neutral parent $\mathrm{PAH}$ is equally efficient. It is concluded that reactions with $\mathrm{H}_{2} \mathrm{O}$ photoproducts are the dominant channel at high temperatures.

7. Spectra from 4000 to $500 \mathrm{~cm}^{-1}$ of the non-volatile room temperature residue that builds up over the course of the experiments on each PAH species considered here are analyzed. These aromatic-rich residues contain $\mathrm{OH}, \mathrm{CO}$, and $\mathrm{CH}_{2}$ groups as evidenced by absorptions in the $\mathrm{OH}$ stretching region $(2.8 \mu \mathrm{m}), \mathrm{CH}$ stretching region $(3.3-3.4 \mu \mathrm{m})$ and in the $\mathrm{C}=\mathrm{O}, \mathrm{C}-\mathrm{O}$, and aromatic $\mathrm{CC}$ region $(5.6-10 \mu \mathrm{m})$.

8. The infrared data of the PAH photoproducts are compared to 5-8 $\mu \mathrm{m}$ ISO and Spitzer spectra of a high- and low-mass protostar. It is shown that $\mathrm{PAH}: \mathrm{H}_{2} \mathrm{O}$ ice photoproducts are plausible candidates for the 6.2 to $6.3 \mu \mathrm{m}$ absorption band associated with interstellar ice and that these may contribute to some of the weak structure between about 6.9 to $8 \mu \mathrm{m}$. The band strength of the 6.2 to $6.3 \mu \mathrm{m}$ band of the $\mathrm{PAH}: \mathrm{H}_{2} \mathrm{O}$ ice photoproducts reported here is determined. From this we derive an upper limit for interstellar abundance of PAHs and $\mathrm{PAH}: \mathrm{H}_{2} \mathrm{O}$ ice photoproducts with respect to $\mathrm{H}_{2} \mathrm{O}$ ice of $2-3 \%$.

Acknowledgements. The authors thank J. V. Keane (ISO-SWS, W33A) and A. C. A. Boogert (Spitzer, RNO 91) for placing the observational spectra at our disposal. This work is financially supported by NASA's Laboratory Astrophysics and Astrobiology Programs, "Stichting voor Fundamenteel Onderzoek der Materie" (FOM), and "the Netherlands Research School for Astronomy" (NOVA). J. Bouwman gratefully acknowledges the "Search for Extraterrestrial Intelligence" (SETI) institute for financial support. The research leading to these results has received funding from the [European Community's] Seventh Framework Programme [FP7/2007-2013] under grant agreement $n^{\circ}$ [238258].

\section{References}

Allamandola, L. J., Tielens, A. G. G. M., \& Barker, J. R. 1985, ApJ, 290, L25 Allamandola, L. J., Tielens, A. G. G. M., \& Barker, J. R. 1989, ApJS, 71, 733 Andersson, S., \& van Dishoeck, E. F. 2008, A\&A, 491, 907

Ashbourn, S. F. M., Elsila, J. E., Dworkin, J. P., et al. 2007, Meteoritics and Planetary Science, 42, 2035

Bauschlicher, Jr., C. W., Peeters, E., \& Allamandola, L. J. 2008, ApJ, 678, 316 
Bauschlicher, C. W., Peeters, E., \& Allamandola, L. J. 2009, ApJ, 697, 311 Bauschlicher, C. W., Boersma, C., Ricca, A., et al. 2010, ApJS, 189, 341 Bellamy, L. J. 1960, The Infra-Red Spectra of Complex Molecules (Wiley) Bernstein, M. P., Sandford, S. A., Allamandola, L. J., et al. 1999, Science, 283, 1135

Bernstein, M. P., Elsila, J. E., Dworkin, J. P., et al. 2002, ApJ, 576, 1115

Bernstein, M. P., Mattioda, A. L., Sandford, S. A., \& Hudgins, D. M. 2005a, ApJ, 626, 909

Bernstein, M. P., Sandford, S. A., \& Allamandola, L. J. 2005b, ApJS, 161, 53

Bernstein, M. P., Sandford, S. A., Mattioda, A. L., \& Allamandola, L. J. 2007, ApJ, 664, 1264

Bisschop, S. E., Fuchs, G. W., Boogert, A. C. A., van Dishoeck, E. F., \& Linnartz, H. 2007, A\&A, 470, 749

Boogert, A. C. A., \& Ehrenfreund, P. 2004, in Astrophysics of Dust, ed. A. N. Witt, G. C. Clayton, \& B. T. Draine, ASP Conf. Ser., 309, 547

Boogert, A. C. A., Schutte, W. A., Tielens, A. G. G. M., et al. 1996, A\&A, 315, L377

Boogert, A. C. A., Schutte, W. A., Helmich, F. P., Tielens, A. G. G. M., \& Wooden, D. H. 1997, A\&A, 317, 929

Boogert, A. C. A., Pontoppidan, K. M., Knez, C., et al. 2008, ApJ, 678, 985

Bouwman, J., Paardekooper, D. M., Cuppen, H. M., Linnartz, H., \& Allamandola, L. J. 2009, ApJ, 700, 56

Bouwman, J., Cuppen, H. M., Bakker, A., Allamandola, L. J., \& Linnartz, H. 2010b, A\&A, 511, A33

Bregman, J. D., \& Temi, P. 2001, ApJ, 554, 126

Bregman, J. D., Hayward, T. L., \& Sloan, G. C. 2000, ApJ, 544, L75

Brooke, T. Y., Sellgren, K., \& Geballe, T. R. 1999, ApJ, 517, 883

Chiar, J. E., Tielens, A. G. G. M., Whittet, D. C. B., et al. 2000, ApJ, 537, 749

Chumbalov, T. K., Chanysheva, I. S., \& Muzychkina, R. A. 1967, J. Appl. Spectroscopy, 6, 570

D’Hendecourt, L. B., \& Allamandola, L. J. 1986, A\&AS, 64, 453

Draine, B. T., \& Li, A. 2007, ApJ, 657, 810

Ehrenfreund, P., \& Charnley, S. B. 2000, ARA\&A, 38, 427

Gibb, E. L. \& Whittet, D. C. B. 2002, ApJ, 566, L113

Gudipati, M. S., \& Allamandola, L. J. 2006, ApJ, 638, 286

Hudgins, D. M., Sandford, S. A., Allamandola, L. J., \& Tielens, A. G. G. M. 1993, ApJS, 86, 713

Hudgins, D. M., Sandford, S. A., \& Allamandola, L. J. 1994, J. Phys. Chem., 98, 4243

Hudgins, D. M., \& Allamandola, L. J. 1995a, J. Phys. Chem., 99, 3033

Hudgins, D. M., \& Allamandola, L. J. 1995b, J. Phys. Chem., 99, 8978

Hudgins, D. M., \& Allamandola, L. J. 1997, J. Phys. Chem. A, 101, 3472

Hudgins, D. M., \& Sandford, S. A. 1998a, J. Phys. Chem. A, 102, 329
Hudgins, D. M., \& Sandford, S. A. 1998b, J. Phys. Chem. A, 102, 344 Jenniskens, P., \& Blake, D. F. 1994, Science, 265, 753

Joblin, C., D’Hendecourt, L., Leger, A., \& Defourneau, D. 1994, A\&A, 281, 923

Keane, J. V. 2001, Ph.D. Thesis, Rijksuniversiteit Groningen

Keane, J. V., Tielens, A. G. G. M., Boogert, A. C. A., Schutte, W. A., \& Whittet, D. C. B. 2001, A\&A, 376, 254

Kerkhof, O., Schutte, W. A., \& Ehrenfreund, P. 1999, A\&A, 346, 990

Langhoff, S. R. 1996, J. Phys. Chem., 100, 2819

Li, A., \& Draine, B. T. 2002, ApJ, 572, 232

Mattioda, A. L., Allamandola, L. J., \& Hudgins, D. M. 2005a, ApJ, 629, 1183

Mattioda, A. L., Hudgins, D. M., Bauschlicher, C. W., \& Allamandola, L. J. 2005b, Adv. Space Res., 36, 156

Milligan, D. E., \& Jacox, M. E. 1969, J. Chem. Phys., 51, 277

Öberg, K. I., Linnartz, H., Visser, R., \& van Dishoeck, E. F. 2009, ApJ, 693, 1209

Peeters, E., Allamandola, L. J., Hudgins, D. M., Hony, S., \& Tielens, A. G. G. M. 2004, in Astrophysics of Dust, ed. A. N. Witt, G. C. Clayton, \& B. T. Draine, ASP Conf. Ser., 309, 141

Pendleton, Y. J., \& Allamandola, L. J. 2002, ApJS, 138, 75

Puget, J. L., \& Leger, A. 1989, ARA\&A, 27, 161

Rapacioli, M., Calvo, F., Joblin, C., et al. 2006, A\&A, 460, 519

Sandford, S. A. 2002, Planet. Space Sci., 50, 1145

Sandford, S. A., \& Allamandola, L. J. 1993, ApJ, 417, 815

Sandford, S. A., Bernstein, M. P., \& Allamandola, L. J. 2004, ApJ, 607, 346

Schutte, W. A., Allamandola, L. J., \& Sandford, S. A. 1993, Science, 259, 1143

Schutte, W. A., Boogert, A. C. A., Tielens, A. G. G. M., et al. 1999, A\&A, 343, 966

Schutte, W. A., \& Khanna, R. K. 2003, A\&A, 398, 1049

Sellgren, K., Brooke, T. Y., Smith, R. G., \& Geballe, T. R. 1995, ApJ, 449, L69

Silverstein, G. C., \& Bassler, R. M. 1967, Spectrometric Identification of Organic Compounds Second Edition (Wiley)

Smith, R. G., Sellgren, K., \& Tokunaga, A. T. 1989, ApJ, 344, 413

Smith, J. D. T., Draine, B. T., Dale, D. A., et al. 2007, ApJ, 656, 770

Szczepanski, J., \& Vala, M. 1993, ApJ, 414, 646

Szczepanski, J., Chapo, C., \& Vala, M. 1993a, Chem. Phys. Lett., 205, 434

Szczepanski, J., Vala, M., Talbi, D., Parisel, O., \& Ellinger, Y. 1993b, J. Chem. Phys., 98, 4494

Szczepanski, J., Drawdy, J., Wehlburg, C., \& Vala, M. 1995a, Chem. Phys. Lett., 245,539

Szczepanski, J., Wehlburg, C., \& Vala, M. 1995b, Chem. Phys. Lett., 232, 221

Tielens, A. G. G. M. 2008, ARA\&A, 46, 289

van Dishoeck, E. F. 2004, ARA\&A, 42, 119

Wexler, A. 1967, Appl. Spectroscopy Rev., 1, 29 